\title{
Regulatory roles of psrA and rpoS in phenazine-1-carboxamide synthesis by Pseudomonas chlororaphis PCL1391
}

Correspondence

Guido V. Bloemberg

bloemberg@rulbim.leidenuniv.nl

Received 21 June 2005

Revised 27 September 2005

Accepted 30 September 2005

\author{
Geneviève Girard, E. Tjeerd van Rij, Ben J. J. Lugtenberg \\ and Guido V. Bloemberg \\ Leiden University, Institute of Biology (IBL), Clusius Laboratory, Wassenaarseweg 64, 2333AL \\ Leiden, the Netherlands
}

\begin{abstract}
Production of the secondary metabolite phenazine-1-carboxamide (PCN) by Pseudomonas chlororaphis PCL1391 is crucial for biocontrol activity against the phytopathogen Fusarium oxysporum f. sp. radicis lycopersici on tomato. Regulation of PCN production involves the two-component signalling system GacS/GacA, the quorum-sensing system Phzl/PhzR and the regulator PsrA. This paper reports that a functional rpoS is required for optimal PCN and $N$-hexanoyl-L-homoserine lactone $\left(\mathrm{C}_{6}-\mathrm{HSL}\right)$ production. Constitutive expression of $r p o S$ is able to complement partially the defect of a psrA mutant for PCN and $\mathrm{N}$-acylhomoserine lactone production. Western blotting shows that $r p o S$ is regulated by gacS. Altogether, these results suggest the existence of a cascade consisting of gacS/gacA upstream of psrA and rpoS, which influence expression of $p h z l / p h z R$. Overproduction of $p h z R$ complements the effects on PCN and $\mathrm{C}_{6}-\mathrm{HSL}$ production of all mutations tested in the regulatory cascade, which shows that a functional quorum-sensing system is essential and sufficient for PCN synthesis. In addition, the relative amounts of $\mathrm{PCN}$, phenazine-1-carboxylic acid and $\mathrm{C}_{6}-\mathrm{HSL}$ produced by rpoS and psrA mutants harbouring a constitutively expressed $p h z R$ indicate an even more complex network of interactions, probably involving other genes. Preliminary microarray analyses of the transcriptomics of the rpoS and psrA mutants support the model of regulation described in this study and allow identification of new genes that might be involved in secondary metabolism.
\end{abstract}

\section{INTRODUCTION}

Secondary metabolites secreted by Gram-negative bacteria are key elements in various interactions with other organisms in the rhizosphere (Bakker et al., 2002; Bassler, 1999; Lugtenberg et al., 2002). In Pseudomonas chlororaphis PCL1391, the production of the antifungal metabolite phenazine-1-carboxamide (PCN) (Chin-A-Woeng et al., 2003) is synthesized through expression of the biosynthetic phzABCDEFGH operon (Chin-A-Woeng et al., 1998). Previous work led to a model of regulation of PCN production involving three different groups of genes: the phzI/ phzR quorum-sensing system (Chin-A-Woeng et al., 2001b), gacS/gacA (global antibiotic and cyanide control), and the regulatory psrA gene (Pseudomonas sigma regulator) (ChinA-Woeng et al., 2005).

The phzI gene is responsible for the synthesis of autoinducers, of which $N$-hexanoyl-L-homoserine lactone

Abbreviations: $\mathrm{C}_{6}-\mathrm{HSL}, \quad \mathrm{N}$-hexanoyl-L-homoserine lactone; $\mathrm{N}$-AHL, $\mathrm{N}$-acylhomoserine lactone; PCA, phenazine-1-carboxylic acid; $\mathrm{PCN}$, phenazine-1-carboxamide.
$\left(\mathrm{C}_{6}-\mathrm{HSL}\right)$ is the main product (Chin-A-Woeng et al., 2001b). $\mathrm{C}_{6}$-HSL is believed to bind to PhzR, thereby activating it. Subsequently, the PhzR- $\mathrm{C}_{6}-\mathrm{HSL}$ complex probably binds to the lux (or phz) box upstream of the phz biosynthetic operon, which results in initiation of the transcription of the phz operon. The PhzR- $\mathrm{C}_{6}$-HSL complex also upregulates phzI via a second $l u x$ box. A similar regulation of phenazine synthesis by quorum sensing was shown in Pseudomonas aureofaciens 30-84 (Pierson et al., 1994).

The GacS/GacA system is composed of a sensor kinase, responding to an unknown (possibly environmental) factor (Heeb et al., 2002; Zuber et al., 2003), and a response regulator belonging to the FixJ family. In Pseudomonas species, GacS and GacA are global regulators of secondary metabolism, since they are situated upstream of many regulatory cascades and seem to function as master regulators. GacS and GacA are involved in the regulation of a substantial set of genes and of multiple traits, such as production of metabolites like HCN and 2,4-diacetylphloroglucinol (Phl) in Pseudomonas fluorescens CHAO (Laville et al., 1992), of enzymes like exoprotease and phospholipase $C$ in 
P. fluorescens CHAO (Sacherer et al., 1994) and of various phenazines in $P$. aureofaciens $30-84$ and Pseudomonas aeruginosa PAO1 (Chancey et al., 1999; Reimmann et al., 1997). GacS and GacA exert their effect on secondary metabolism by modulating the expression of various regulators (Chatterjee et al., 2003; Haas \& Defago, 2005), including quorum sensing (Bertani \& Venturi, 2004; Chancey et al., 1999; Reimmann et al., 1997) and $\sigma^{\text {s }}$ (Schmidt-Eisenlohr et al., 2003; Whistler et al., 1998). In P. chlororaphis strain PCL1391, a mutation in gacS results in a severe decrease of PCN production to undetectable levels, while the $\mathrm{N}$ acylhomoserine lactone (N-AHL) production is also much lower than in the wild-type (Chin-A-Woeng et al., 2005).

$\mathrm{GacS} / \mathrm{GacA}$ is also required for $p s r A$ expression in $P$. chlororaphis PCL1391 (Chin-A-Woeng et al., 2005). The psrA gene of Pseudomonas putida was shown to regulate the transcription of the rpoS gene (Kojic \& Venturi, 2001) by directly binding to the rpoS promoter (Kojic et al., 2002). rpoS encodes the stationary-phase alternative sigma factor $\sigma^{\mathrm{s}}$, which is responsible for the switch in gene expression occurring upon exposure of cells to starvation and/ or various stresses (Lange \& Hengge-Aronis, 1991). In Pseudomonas species, rpoS mutants are often affected in their secondary metabolism, and particularly in their antibiotic production (Sarniguet et al., 1995; Suh et al., 1999). However, the results are different depending on the species and the antibiotic considered. For example, an rpoS mutation results in a decrease of pyrrolnitrin production by $P$. fluorescens, but in an increase of pyoluteorin and 2,4diacetylphloroglucinol production by the same strain (Sarniguet et al., 1995) and of pyocyanin in P. aeruginosa (Suh et al., 1999).

Here we describe rpoS in P. chlororaphis PCL1391 and its role in the synthesis of PCN. A significant number of PCL1391 derivatives were constructed that are affected in the expression of the $p s r A, r p o S$ and $p h z R$ genes. Quantification of PCN and $\mathrm{C}_{6}$-HSL, as well as preliminary microarray analyses, showed that the phz operon is regulated by a cascade involving GacS, PsrA, RpoS and PhzI/PhzR. In addition, the microarray survey allowed us to identify new genes of the $p s r A / r p o S$ regulon that might be involved in secondary metabolism.

\section{METHODS}

Bacterial strains and growth conditions. The bacterial strains used in this study are listed in Table 1. Pseudomonas strains were cultured at $28^{\circ} \mathrm{C}$ in liquid MVB1 (van Rij et al., 2004) and shaken at 195 r.p.m. on a Janke und Kunkel shaker KS501D (IKA Labortechnik). E. coli strains were grown at $37^{\circ} \mathrm{C}$ in Luria-Bertani medium (Sambrook \& Russell, 2001) under vigorous aeration. LC medium, used for some experiments as indicated in the text, contained $10 \mathrm{~g}$ Bactotryptone (Difco) $1^{-1}, 5$ g yeast extract $1^{-1}, 137 \mathrm{mM}$

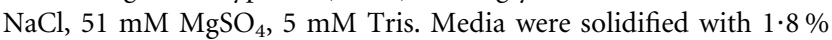
Bacto agar (Difco). When appropriate, growth media were supplemented with kanamycin $\left(50 \mu \mathrm{g} \mathrm{ml}^{-1}\right)$, carbenicillin $\left(200 \mu \mathrm{g} \mathrm{ml}^{-1}\right)$ and gentamicin $\left(10 \mu \mathrm{g} \mathrm{ml}^{-1}\right.$ for Escherichia coli and $30 \mu \mathrm{g} \mathrm{ml}^{-1}$ for P. chlororaphis), and X-Gal $\left(40 \mu \mathrm{ml}^{-1}\right)$. To follow growth, the optical density of liquid cultures was measured at $620 \mathrm{~nm}$.

Construction of vectors and PCL1391 mutant strains. PCRs were in general carried out with Super Taq enzyme (Enzyme Technologies). However, for the production of genes under $\mathrm{P}_{\text {tac }}$ promoter control for complementations, PCRs were done with Proof Start (Qiagen). Primers were synthesized by Isogen Life Science. Restriction enzymes were purchased from New England BioLabs and ligase from Promega. The plasmids and primers used in this study are listed in Tables 1 and 2, respectively.

Degenerate primers were designed from the rpoS genes of $P$. aeruginosa, P. fluorescens and P. putida. These primers (oMP768 and oMP769) were used for PCR of chromosomal DNA of PCL1391 and resulted in the amplification of a DNA fragment of $0.7 \mathrm{~kb}$. Sequencing showed that this fragment shared high homologies (see Results) with rpoS genes of other Pseudomonas strains. Subsequently, primers oMP770 and oMP771 were designed based on the partial rpoS sequence and used in PCR on a pBlueScript chromosomal library of PCL1391 (Chin-A-Woeng et al., 2001b) in combination with oMP49 and oMP50, which anneal close to the multi-cloning site of pBlueScript. oMP770 in combination with oMP49 produced a fragment of $1.2 \mathrm{~kb}$ containing the flanking region upstream of rpoS. oMP771 in combination with oMP50 produced a PCR fragment of $1.8 \mathrm{~kb}$ that contained the flanking regions downstream of rpoS. A third primer was designed for further sequencing of the $3^{\prime}$ downstream region with the same method (oMP772), which in combination with oMP50 produced a $1 \cdot 2 \mathrm{~kb}$ PCR fragment.

In order to construct an rpoS mutant derivative of PCL1391, two primers (oMP773 and oMP774) were used in PCR on the chromosomal DNA of PCL1391, and an internal fragment of $0.5 \mathrm{~kb}$ of the rpoS gene was obtained. This fragment was ligated into pGEM-T easy (Promega) to obtain pMP7425. An EcoRI digestion of pMP7425 produced an EcoRI internal fragment of rpoS which was cloned into the suicide plasmid pMP5285, resulting in pMP7418. This vector was transformed into PCL1391 for single homologous recombination by triparental mating using pRK2043 as helper. The rpoS mutant of PCL1391 that was obtained was checked by Southern blotting and by PCR with oMP686 primer (annealing on pMP5285 close to the multi-cloning site) and oMP776 (annealing on the rpoS $3^{\prime}$ end which is not present in pMP7418) and named PCL1954.

Two primers were designed according to the sequence of the newly characterized rpoS gene of PCL1391 (oMP775 and oMP776), in order to produce a PCR fragment containing the whole rpoS under control of the $\mathrm{P}_{t a c}$ promoter and a part of the $3^{\prime}$ downstream region of rpoS including the putative terminator. The PCR fragment obtained had the expected size of $1.2 \mathrm{~kb}$ and was checked by restriction analysis and sequencing. Subsequently it was cloned into pGEM-T easy, which yielded pMP7424. The $\mathrm{P}_{t a c}$ rpoS fragment was isolated from pMP7424 by EcoRI digestion and ligated into pBBR1MCS-5 to produce pM7420, which was transformed into PCL1391 and PCL1954 by triparental mating to produce PCL1958 and PCL1955, respectively. The control strains PCL1960 and PCL1957 were obtained by transforming the cloning vector pBBR1MCS-5 into PCL1391 and PCL1954, respectively. pMP7420 and pBBR1MCS-5 were also transformed into the psrA mutant PCL1111 to obtain PCL1961 and PCL1962, respectively.

Two primers (oMP777 and oMP778) were used with pMP4030 as template to produce a PCR fragment containing the $p h z R$ gene under $\mathrm{P}_{\text {tac }}$ control. This product was digested by $\mathrm{XhoI}$ and EcoRI and ligated into Xhol/EcoRI-digested pBBR1MCS-5 to obtain pMP7447, which was validated by sequencing and its ability to restore a wild-type PCN 
Table 1. Bacterial strains and plasmids

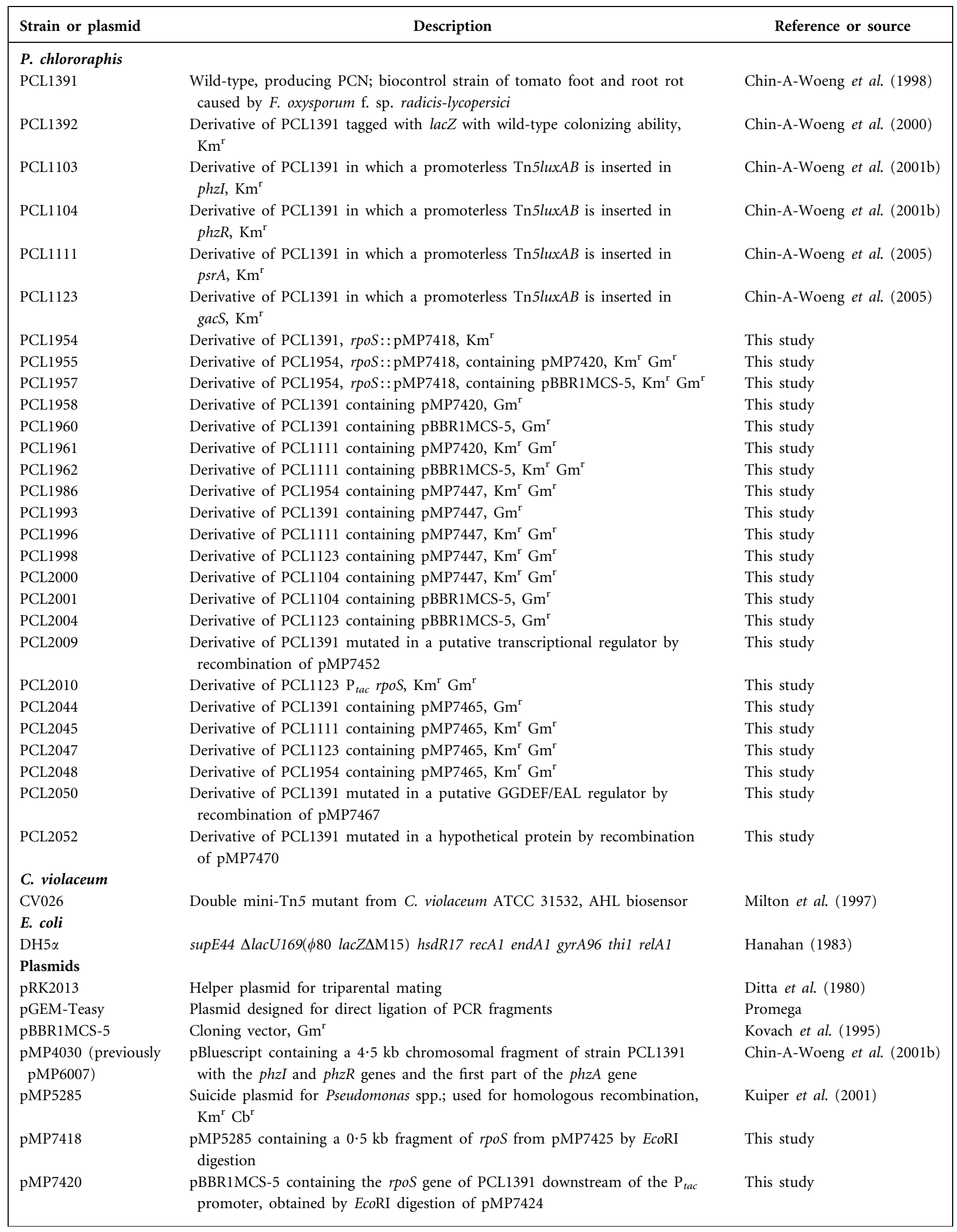


Table 1. cont.

\begin{tabular}{|c|c|c|}
\hline Strain or plasmid & Description & Reference or source \\
\hline pMP7424 & $\begin{array}{l}\text { pGEM-T containing rpoS of PCL1391 downstream of the } \mathrm{P}_{\text {tac }} \text { promoter, } \\
\text { obtained by PCR }\end{array}$ & This study \\
\hline pMP7425 & $\begin{array}{l}\text { pGEM-T containing a } 0.5 \mathrm{~kb} \text { PCR product of the central part of } r p o S \text { of } \\
\text { PCL1391 }\end{array}$ & This study \\
\hline pMP7447 & $\begin{array}{l}\text { pBBR1MCS- } 5 \text { containing } p h z R \text { of PCL1391 downstream of the } \mathrm{P}_{t a c} \text { promoter, } \\
\text { inserted between the XhoI and EcoRI sites }\end{array}$ & This study \\
\hline pMP7452 & $\begin{array}{l}\text { pMP5285 containing a } 0 \cdot 4 \mathrm{~kb} \text { PCR product of an internal part of a putative } \\
\text { transcriptional regulator gene sequenced in microarray clone } 76 \_\mathrm{G} 2\end{array}$ & This study \\
\hline pMP7465 & $\begin{array}{l}\text { pBBR1MCS-5 containing psrA of PCL1391 downstream of the } \mathrm{P}_{t a c} \text { promoter, } \\
\text { inserted in the EcoRI site }\end{array}$ & This study \\
\hline pMP7467 & $\begin{array}{l}\text { pMP5285 containing a } 0 \cdot 4 \mathrm{~kb} \text { PCR product of an internal part of a putative } \\
\text { GGDEF/EAL regulator gene sequenced in microarray clone } 42 \text { G8 }\end{array}$ & This study \\
\hline pMP7470 & $\begin{array}{l}\text { pMP5285 containing a } 0 \cdot 5 \mathrm{~kb} \text { PCR product of an internal part of a } \\
\text { hypothetical protein gene sequenced in microarray clones } 76 \_ \text {G2 and } 47 \text { F5 }\end{array}$ & This study \\
\hline
\end{tabular}

production in the phzR mutant PCL1104. The resulting strain PCL2000 was able to produce PCN (not shown), in contrast to the PCL1104 derivative PCL2001, which contained the cloning vector pBBR1MCS-5. pMP7447 was also transformed into PCL1391, PCL1954, PCL1111 and PCL1123 to obtain PCL1993, PCL1986, PCL1996 and PCL1998, respectively.

Primers oMP859 and oMP861 were used with chromosomal DNA as template to produce a PCR fragment containing the $p s r A$ gene. This fragment was used as template for PCR with oMP860 and oMP861 to obtain the $p s r A$ gene under $\mathrm{P}_{t a c}$ promoter control. This fragment was digested with EcoRI and ligated into the EcoRI site of pBBR1MCS-5, to obtain pMP7465. pMP7465 was validated by sequencing. pMP7465 was subsequently transformed into PCL1391, PCL1111, PCL1123 and PCL1954 to obtain PCL2044, PCL2045, PCL2047 and PCL2048, respectively.

Three mutants were constructed in genes selected by microarray analyses. The genes chosen were a putative transcriptional regulator gene found in microarray clone 76_G2, a putative GGDEF/EAL regulator found in microarray clone 42 G8 and a hypothetical protein found in microarray clones 76_G2 and 47_F5. Primers oMP810 and oMP811, oMP972 and oMP973, oMP977 and oMP978 were used with clone 76_G2, clone 42_G8 and chromosomal DNA as a template, respectively, to produce an internal fragment of $0.4 \mathrm{~kb}$ for the putative transcriptional regulator gene, $0 \cdot 4 \mathrm{~kb}$ for the putative GGDEF/EAL regulator gene and $0.5 \mathrm{~kb}$ for the hypothetical protein gene, respectively. The PCR products obtained were cloned in the EcoRI site of pMP5285, resulting in pMP7452, pMP7467 and pMP7470, respectively. These vectors were transformed into PCL1391 to obtain PCL2009, PCL2050 and PCL2052, respectively. The mutations were verified by PCR and/or sequencing.

Extraction and analysis of phenazine and $\mathbf{N}$-AHL. Phenazine extraction was carried out from $10 \mathrm{ml}$ MVB1 liquid cultures in $100 \mathrm{ml}$ Erlenmeyer flasks at regular time points during growth and/ or after overnight growth of bacterial strains as described previously (van Rij et al., 2004).

For extraction of $\mathrm{N}$-AHL, supernatants from $50 \mathrm{ml}$ liquid MVB1 cultures in $500 \mathrm{ml}$ Erlenmeyer flasks were mixed with 0.7 vol. dichloromethane, and shaken for $1 \mathrm{~h}$, after which the organic phase was collected. Each supernatant was extracted twice and the pooled extracts were dried using a rotary evaporator. The dried residue was dissolved in $25 \mu \mathrm{l}$ acetonitrile and spotted on C18 TLC plates (Merck). As a control, $0 \cdot 5 \mu \mathrm{l}$ synthetic $\mathrm{C}_{6}$-HSL $(5 \mu \mathrm{M})$ (Fluka) was spotted on the TLC plate. The plates were developed in methanol/water $(60: 40, \mathrm{v} / \mathrm{v})$. For detection of $\mathrm{N}$-AHL, the TLC was overlaid with $0 \cdot 8 \%$ LC agar containing a 10-fold diluted overnight culture of the Chromobacterium violaceum indicator strain CV026 and supplemented with kanamycin $\left(50 \mu \mathrm{g} \mathrm{ml}^{-1}\right)$. After incubation for $48 \mathrm{~h}$ at $28^{\circ} \mathrm{C}$, chromatograms were judged for appearance of violet spots.

Western blot analysis. Cells were grown after inoculation of $10 \mathrm{ml}$ MVB1 from an overnight culture diluted to $\operatorname{OD}_{620} 0 \cdot 1$. Cells were harvested at $\mathrm{OD}_{620} 1 \cdot 0$ or $2 \cdot 2$ in volumes of culture corrected for their differences in $\mathrm{OD}_{620}$ to obtain similar amounts of cells. Cell pellets were suspended in $200 \mu \mathrm{l}$ cracking buffer ( $50 \mathrm{mM}$ Tris/ $\mathrm{HCl} \mathrm{pH} 6 \cdot 8,1 \%$ SDS, 2 mM EDTA, $10 \%$, v/v, glycerol, $0 \cdot 01 \%$ bromophenol blue, $1 \% \beta$-mercaptoethanol) and boiled for $3 \mathrm{~min}$. The samples were subsequently loaded on a $10 \%$ SDS-PAGE gel and proteins were separated and transferred on to a blot following a standard Western blot procedure (Ausubel et al., 1997). A dry aliquot of RpoS antibodies was kindly provided by Professor K. Tanaka (Tokyo, Japan). The pellet was suspended in $100 \mu \mathrm{l}$ PBS and diluted 1000-fold for reaction with immobilized protein, as recommended. Peroxidase-labelled goat anti-rabbit antiserum (Amersham Biosciences) was subsequently incubated with the blots. Finally, blots were incubated in luminal solution $[250 \mu \mathrm{M}$ sodium luminol (Sigma), 0.1 M Tris/ $\mathrm{HCl}, \mathrm{pH} \mathrm{8.6,0.01 \%} \mathrm{H}_{2} \mathrm{O}_{2}$ ] mixed with $60 \mu \mathrm{l}$ enhancer solution $[67 \mu \mathrm{M}$ p-hydroxycoumaric acid (Sigma) in DMSO]. Hybridizing protein bands were visualized on Super R-X photographic film (Fujifilm) after chemiluminescence detection.

RNA preparation, cDNA probe generation and microarray processing. The methods followed were described previously (van Rij et al., 2005). Briefly, $12 \mathrm{ml}$ MVB1 medium was inoculated in $100 \mathrm{ml}$ flasks to an $\mathrm{OD}_{620}$ of $0 \cdot 1$ from overnight cultures of $P$. chlororaphis PCL1391 or derivative strains. The cultures were shaken at $28^{\circ} \mathrm{C}$ at a speed of 195 r.p.m. on a Janke und Kunkel shaker KS501D until the $\mathrm{OD}_{620}$ reached a value of $2 \cdot 0$. This optical density corresponds to the moment where PCN starts to be produced (see Fig. 2), which indicates that the genes regulating the $p h z$ operon are probably expressed. After phenol/chloroform extraction, the water phase was applied on columns from the RNeasy Midi kit (Qiagen), and the RNA was extracted following the protocol supplied by the manufacturer, including the DNase step. RNA purity was verified on $1 \cdot 2 \%$ agarose gel following the protocol of the RNeasy Midi kit (Qiagen). RNA was immediately used for cDNA probe generation 
Table 2. Oligonucleotides

\begin{tabular}{|c|c|}
\hline Name & Nucleotide sequence $\left(5^{\prime}-3^{\prime}\right)$ \\
\hline oMP49 & CAGGAAACAGCTATGACCATGATTAC \\
\hline oMP50 & CCCAGTCACGACGTTCTAAAACG \\
\hline oMP500 & CCCAAGCTTCGGTGGACTTCACTGGC \\
\hline oMP501 & CCCAAGCTTGGCACACGTACCTCAAGGCT \\
\hline oMP582 & GGAATTCGGTGAAATAGCCTCCCAACA \\
\hline oMP583 & GGAATTCGGTCATCTTCGATGGTCAGG \\
\hline oMP604 & CCCAAGCTTTCGGCGTAGATCATGGGGGTGTGC \\
\hline oMP605 & CCCAAGCTTGCGCCGGGGCGCCGCCCAAGCATCC \\
\hline oMP652 & GGAATTCGCCCGCCTGCAYCARCARGGSCARTCC \\
\hline oMP653 & GGAATTCAGCAGATGGCTGGCGAAGGAGTGYCG \\
\hline oMP686 & TTAAGTTTATTCTTATCAATATAGG \\
\hline oMP689 & CGCGGATCCGGCTGCTGGAACGCTACACA \\
\hline oMP690 & CGCGGATCCACGGTCGAGCAATATATGCG \\
\hline oMP768 & AAMGAAGBGCCGGAGTTTGAC \\
\hline oMP769 & GTRTCSAGCAGGGTCTTGTCCGA \\
\hline oMP770 & CAGTGGCGATGTCCGTCTCC \\
\hline oMP771 & CTCGACCATGAACCCTCCСС \\
\hline oMP772 & TCCTGCCGTTGAAAACCCCG \\
\hline oMP773 & AAGCAACCTGCGTCTGGTGG \\
\hline oMP774 & CGATGCTTTGCGACAGGTCG \\
\hline oMP775 & $\begin{array}{l}\text { ATATATGAATTCTTGACAATTAATCATCGGCTCGTATAATGTGTGGAA- } \\
\text { TTGTGAGCGGATAACAATTTTCACACAGGAAACAGCTAAATGGCTCT- } \\
\text { CAGTAAAGAAGTGCCGGAGTTTGACATCGACG }\end{array}$ \\
\hline oMP776 & ATATATGGATCCGGGATTCCGTGAAGAACCAATAAAAAGCCCC \\
\hline oMP777 & $\begin{array}{l}\text { ATATATCTCGAGTTGACAATTAATCATCGGCTCGTATAATGTGTGGAA- } \\
\text { TTGTGAGCGGATAACAATTTTCACACAGGAAACAGCTAAATGGAGTT- } \\
\text { AGGGCAGCAGTTGGGATGGG }\end{array}$ \\
\hline oMP778 & ATATATGAATTCCCCCTCAGATATAGCCCATCGCAACTGCG \\
\hline oMP783 & GGGGTACCGGCGGTGAATTATCATTTCG \\
\hline oMP784 & GGGAATTCGGAATACCTTGCCGTACATG \\
\hline oMP689 & CGCGGATCCGGCTGCTGGAACGCTACACA \\
\hline oMP690 & CGCGGATCCACGGTCGAGCAATATATGCG \\
\hline oMP810 & CAAGAGTTCGCTGGCGGTGG \\
\hline oMP811 & GATTCGTCGTAGGTCAGGCG \\
\hline oMP836 & ATATATGAATTCTCAGAAGAACTCGTCAAGAAGGCG \\
\hline oMP837 & ATATATCTCGAGATGATTGAACAAGATGGATTGCACG \\
\hline oMP859 & ATGGCCCAGTCGGAAACCGTTGAACGC \\
\hline oMP860 & $\begin{array}{l}\text { ATATATGAATTCTTGACAATTAATCATCGGCTCGTATAATGTGTGGAA- } \\
\text { TTGTGAGCGGATAACAATTTTCACACAGGAAACAGCTAAATGGCCCA- } \\
\text { GTCGGAAACCGTTGAACGC }\end{array}$ \\
\hline oMP861 & ATATATGAATTCCCGCGCCCACCCGGACGGTCAGGCC \\
\hline oMP972 & ATATATGAATTCCTCGGTATTTCGCTACGGTTCGG \\
\hline oMP973 & ATATATGAATTCCCCAGCCATGGCCGGGCCGG \\
\hline oMP977 & ATATATGAATTCGGGAAACTACAAGATGCCGG \\
\hline oMP978 & ATATATGAATTCTCGAGGGTTTCGTGCACCAG \\
\hline
\end{tabular}

using the CyScribe post-labelling kit (Amersham Biosciences). After purification, the efficiency of Cy label incorporation into the cDNA and the quality and amounts of labelled cDNA were verified with an Ultrospec 2100 pro spectrophotometer (Amersham Biosciences). Equal amounts of each dye were hybridized on the microarray. A minimum of $45 \mathrm{pmol}$ of each dye was hybridized.

Construction of the chromosomal microarray of $P$. chlororaphis PCL1391 was described previously (van Rij et al., 2005). Before hybridization, the DNA on the microarrays was UV-cross-linked at $250 \mathrm{~mJ} \mathrm{~cm}{ }^{-2}$ (Amersham LifeSciences UV cross-linker). After prehybidization and washing of the slides, the Cy-labelled cDNA was hybridized on the microarrays overnight at $65^{\circ} \mathrm{C}$ in a GeneTAC Hybstation (Genomic Solutions). After washing and drying, the slides were scanned in a G2565AA Microarray Scanner (Agilent).

Each experiment was repeated at least four times, including at least two independent experiments and a dye swap. Each experiment 
included as 'test' the Cy-labelled cDNA deriving from the RNA of a mutant, and as 'reference' the Cy-labelled cDNA deriving from the RNA of the wild-type.

Microarray data analysis. After scanning, the microarrays were analysed in GenePix Pro version 4.0. The values were normalized assuming that most genes of the array are not differentially expressed. Several criteria were implemented to select spots corresponding to differentially expressed genes: spots were selected if the mean of the ratio of red and green laser intensities was higher than 2 [in GenePixPro: Ratio of Medians $(650 / 550)>2$ ] or lower than $0 \cdot 5$, but positive [in GenePixPro: Ratio of Medians $(650 / 550)<0 \cdot 5$ and Ratio of Medians $(650 / 550)>0$ ]. These values of 2 and 0.5 were arbitrarily chosen to select genes of which the expression is increased or decreased at least twofold in the rpoS or psrA mutant as compared to the wild-type. In both cases, the spots were selected only if they had at least $80 \%$ of their feature pixels more than two standard deviations above background in both the green and red channels [in GenePixPro: $(\%>B 550+2$ SD $)>80$ and $(\%>B 650+2$ SD $)>80]$. This condition prevents the selection of spots from which the feature intensity is too close to the background. As additional selection criteria, spots that had intensities lower than the intensity of the $\lambda$ control in both the red and green channel were eliminated. This eliminates spots where labelled cDNA hybridized non-specifically to the spotted DNA. In order to avoid false positives due to problems of uniformity of the background and/or the feature, all the selected spots were finally controlled directly on the image of the scan.

Phenotypic analyses of mutants deriving from microarray analyses. Bacteria were tested for protease production as described by Chin-A-Woeng et al. (1998), except that the concentration of milk was increased to $10 \%$ in MVB1 agar plates.

To test swimming and swarming ability, the method described by Deziel et al. (2001) was used, in which $1 / 20 \mathrm{~KB}-0 \cdot 3 \%$ agar plates were used for the swimming, and $1 / 20 \mathrm{~KB}-0 \cdot 5 \%$ agar plates were used for swarming.

For measuring the production of chitinase, plates were poured with $2 \%$ agar dissolved in $0.05 \mathrm{M}$ sodium acetate and Cm-Chitin-RBV solution (Loewe Biochemica), following recommendations of the manufacturer. Samples $(200 \mu \mathrm{l})$ of supernatant of 3-day-old LC cultures were applied in wells made in the plates. After overnight incubation at $28^{\circ} \mathrm{C}$, the formation of a halo was verified.

The production of hydrogen cyanide $(\mathrm{HCN})$ was measured as described by Castric (1975). Whatman 3MM paper was soaked in a chloroform solution containing copper(II) ethyl acetoacetate $\left(5 \mathrm{mg} \mathrm{ml}^{-1}\right)$ and 4,4'-methylene-bis-( $N, N$-dimethylaniline $)\left(5 \mathrm{mg} \mathrm{ml}^{-1}\right)$, and subsequently dried and stored in the dark. A piece of paper was placed in the lid of a Petri dish in which bacteria had been plated on MVB1 agar (1\%). The Petri dishes were incubated overnight at $28^{\circ} \mathrm{C}$. Production of $\mathrm{HCN}$ by the bacteria was indicated by blue colouration of the paper.

\section{RESULTS}

\section{Identification of rpoS in $\boldsymbol{P}$. chlororaphis PCL1391}

Using degenerate primers based on known Pseudomonas rpoS sequences, a PCR fragment was obtained with chromosomal DNA of PCL1391 as a template. After sequencing of this fragment, flanking chromosomal regions were isolated by PCR using a pBlueScript chromosomal library from PCL1391 as the template (for details see Methods).
Sequence analyses of the $P$. chlororaphis PCL1391 fragments confirmed the presence of an ORF (accession no. AY586457) encoding a protein of 335 amino acids, which showed an identity of $99 \%$ with $r p o S$ of $P$. chlororaphis strain 06 (Kang et al., 2004), $97 \%$ with rpoS of $P$. fluorescens PfO1 (accession no. ZP_00266495.1), $93 \%$ with rpoS of P. putida (Kojic et al., 1999), and $93 \%$ with rpoS of P. syringae pv. tomato DC3000 (accession no. NP_791390).

A putative Shine-Dalgarno sequence was detected starting $12 \mathrm{nt}$ upstream of the start codon, and a putative rho-independent terminator sequence is present $22 \mathrm{nt}$ downstream of the stop codon. In addition a sequence (GAAACTGCACTTTG) was identified close to the ATG codon in the promoter of the PCL1391 rpoS homologous gene, identical to the PsrA binding box consensus of $P$. putida (Kojic et al., 2002).

The ORF upstream of PCL1391 rpoS is homologous (98\% identity) to the lipoprotein gene $n l p D$ of $P$. chlororaphis 06 (Kang et al., 2004). The ORF sequence identified downstream of $r p o S$ shows homology ( $50 \%$ identity) to a transposase gene of Ralstonia solanacearum (accession no. NP_5 20694.1).

In contrast, rpoS of other Pseudomonas strains is followed by the small RNA regulator $r s m Z$ (regulator of secondary metabolites) and $f d x A$ (ferredoxin A) (Heurlier et al., 2004).

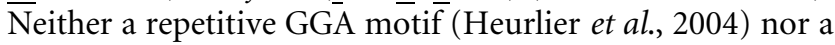
conserved upstream element (Heeb et al., 2002) indicating the presence of an rsm Z homologue downstream of rpoS were found in PCL1391. Alignment analysis using Vector NTI with $r s m Z$ sequences of several Pseudomonas species with a $500 \mathrm{nt}$ sequence downstream of rpoS in PCL1391 did not show any homology (not shown).

\section{Effect of rpoS on PCN and $\mathbf{N}$-AHL production}

A 500 bp internal fragment of $r p o S$ was generated by PCR and used for single homologous recombination in strain PCL1391, resulting in PCL1954 (for details see Methods). Western blot analysis showed that the RpoS protein was absent in PCL1954 (Fig. 1, lane 6). The production of PCN by the rpoS mutant PCL1954 was decreased by $99 \%$ compared to that by PCL1391 (Fig. 2a, b). Constitutive

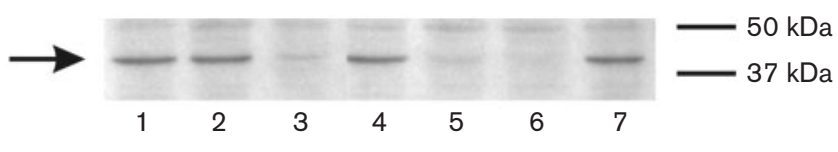

Fig. 1. Western blot analysis of RpoS production in $P$. chlororaphis PCL1391 and derivative strains. Lanes: 1, PCL1391; 2, PCL1103 (phzl::Tn5/uxAB); 3, PCL1111 (psrA::Tn5luxAB); 4, PCL1119 (phzB::Tn5/uxAB); 5, PCL1123 (gacS::Tn5/uxAB); 6, PCL1954 (rpoS::pMP7418); 7, PCL1955 (rpoS::pMP7418+ $\left.\mathrm{P}_{\text {tac }} r p o S\right)$. On the right side of the blot two markers are shown. The arrow on the left indicates the position of RpoS. 

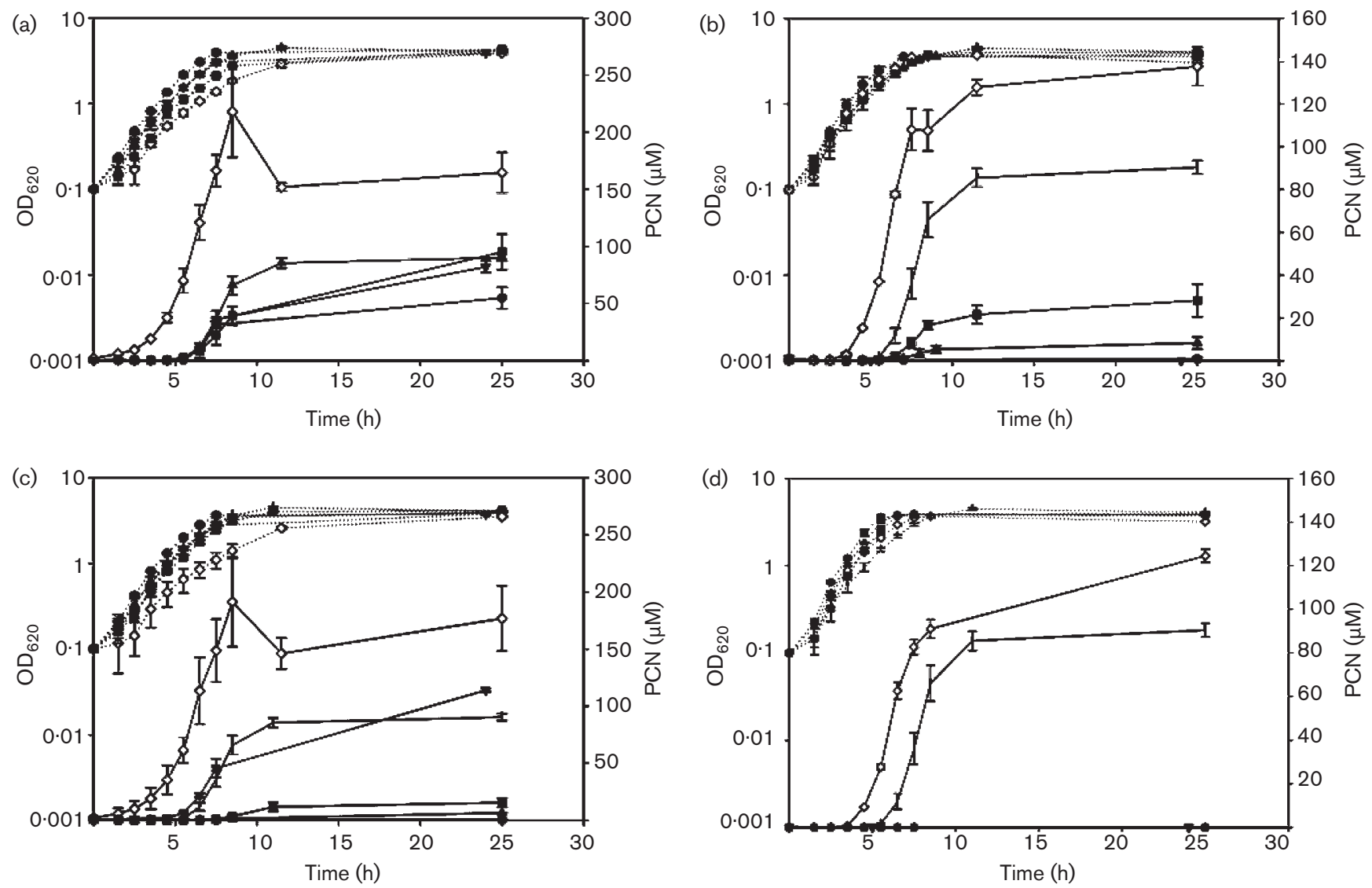

Fig. 2. PCN production by $P$. chlororaphis PCL1391 and derivative strains. Extractions were made at intervals from at least three independent cultures in $10 \mathrm{ml} \mathrm{MVB1}$ and the PCN concentration was determined by HPLC. On each graph, the culture $\mathrm{OD}_{620}$ is plotted on the left axis (dotted lines) and the PCN concentration is plotted on the right axis (full lines). For easier reading, the same symbols are used in the different panels for the following constructs: original strain ( $\bullet$ ), derivative containing pBBR1MCS-5 $(\boldsymbol{\Delta})$, derivative containing $\mathrm{P}_{\text {tac }} r p o S(\boldsymbol{\square})$, derivative containing $\mathrm{P}_{\text {tac }}$ phzR $(\diamond)$, derivative containing $\mathrm{P}_{\text {tac }} \operatorname{psr} A(\boldsymbol{\nabla})$. For panels (b), (c) and (d), the values for PCL1960 (PCL1391 + pBBR1MCS-5) are plotted as a control (l).

(a) Wild-type derivatives; (b) rpoS derivatives; (c) psrA derivatives; (d) gacS derivatives. The error bars represent SD.

expression of rpoS was established by cloning rpoS under control of the tac promoter in the vector pBBRMCS-5, resulting in pMP7420 (for details see Methods). In the derivative PCL1955 ( $r p o S$ mutant with $\mathrm{P}_{t a c} r p o S$ ), the production of RpoS was shown using Western blot analysis (Fig. 1, lane 7) and PCN production was restored to between $35 \%$ (Fig. 2b) and $70 \%$ (Fig. 3a) of that of the control strain PCL1960 (wild-type + pBBR1MCS-5).

The production of $\mathrm{C}_{6}$-HSL by the rpoS mutant was much decreased, but detectable (Fig. 3a). $\mathrm{C}_{6}$-HSL levels in an rpoS mutant background were restored by the constitutive production of RpoS in PCL1955 (Fig. 3a).

Since a defect in rpoS decreased PCN production, the effect of overexpression of rpoS in the wild-type strain PCL1391 was also analysed by transforming pMP7420 into PCL1391. No major difference was observed between the amounts of PCN produced by wild-type PCL1391 with constitutive expression of rpoS and wild-type PCL1391 containing the empty cloning vector (Fig. 2a).

\section{Interactions between quorum sensing and rpoS and their influence on PCN production}

The observations that the amounts of $\mathrm{PCN}$ and $\mathrm{C}_{6}$-HSL are decreased in an rpoS mutant, and restored by the constitutive expression of $r p o S$, indicate that RpoS regulates the $p h z$ operon via $p h z R$ and/or $p h z I$. Therefore the effect of constitutive expression of $p h z R$ in the rpoS mutant was tested. For this purpose $p h z R$ was cloned under the control of the tac promoter, resulting in plasmid pMP7447, and transformed into the rpoS mutant PCL1954. The resulting strain PCL1986 showed complementation for PCN production of the rpoS mutation, as it produced 1.5-fold higher PCN than PCL1391 harbouring empty pBBR1MCS-5 (Fig. 2b) and showed increased $\mathrm{C}_{6}$-HSL production (Fig. $3 \mathrm{~b}$ ). 


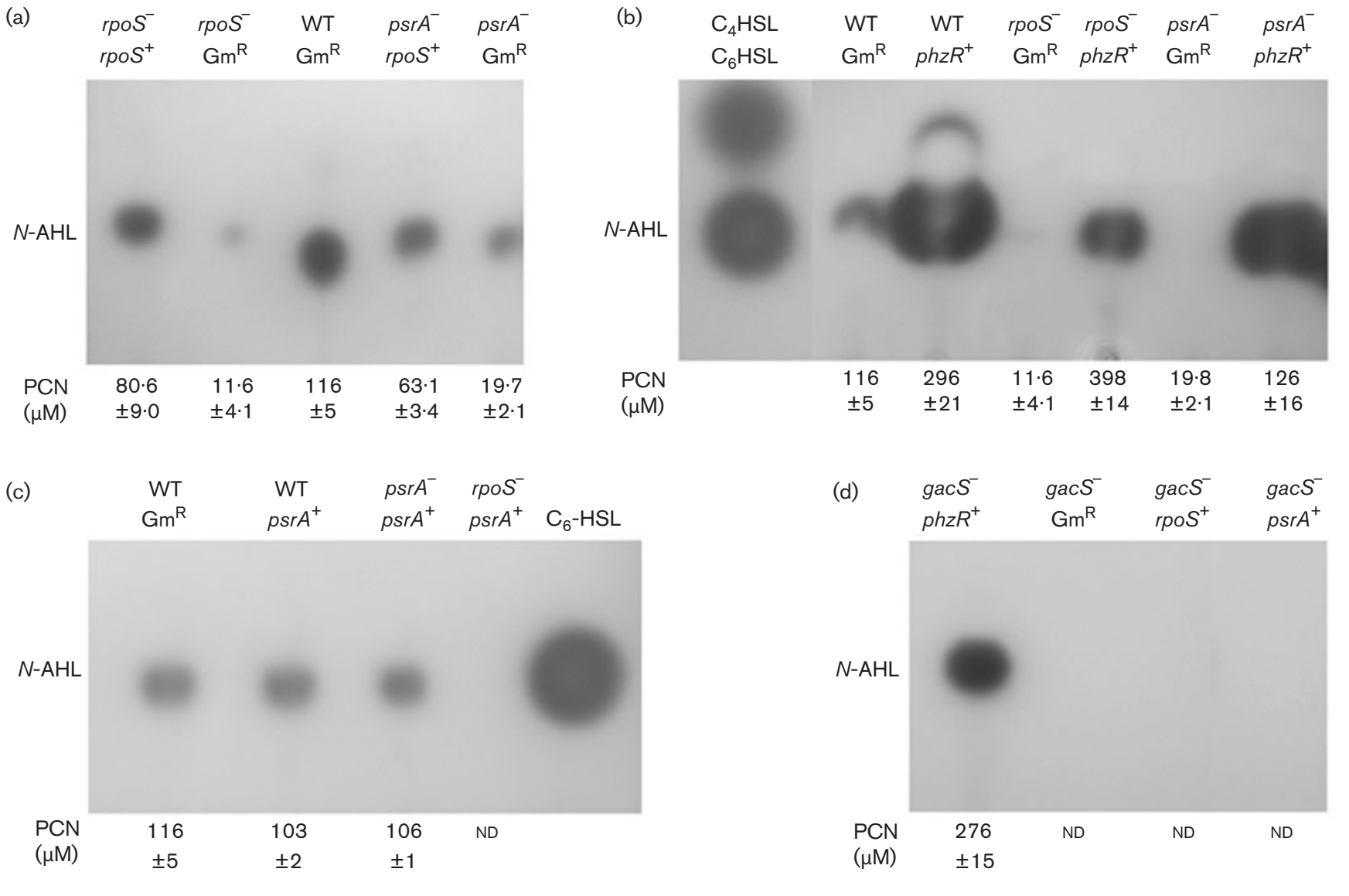

Fig. 3. C18-reverse phase TLC analysis of $N$-AHLs produced by $P$. chlororaphis PCL1391 derivatives in $50 \mathrm{ml}$ MVB1. On each panel a group of PCL1391 derivatives is analysed. The strains are described above the TLC image: WT indicates a wildtype derivative, $p s r A^{-}$a PCL1111 derivative and $r p o S^{-}$a PCL1954 derivative; on the second line, $\mathrm{Gm}^{\mathrm{R}}$ indicates the presence of the empty vector pBBR1MCS-5 in the derivative, phz $R^{+}$the presence of pMP7444 overexpressing phzR, rpoS ${ }^{+}$ the presence of pMP7420 overexpressing $r p o S$ and $p s r A^{+}$the presence of pMP7465 overexpressing $p s r A$. The numbers under the TLC image indicate the PCN production after overnight growth in $50 \mathrm{ml} \mathrm{MVB1}$ for each PCL1391 derivative. These numbers are means and standard deviations calculated from extractions made in at least three independent cultures (ND, not detectable). The PCN concentration was determined by HPLC.

\section{Regulation of RpoS synthesis by genes involved in PCN synthesis}

The effect of mutations in gacS, psrA, phzI or $p h z B$ of PCL1391 on the production of RpoS protein was tested by Western blot analysis. The experiments were performed in MVB1 medium and samples for RpoS analysis were harvested during exponential phase $\left(\mathrm{OD}_{620} 1 \cdot 0\right)$ and at the beginning of the stationary phase $\left(\mathrm{OD}_{620} 2 \cdot 2\right)$. The amounts of RpoS appeared to be similar at the two time points. A blot of the results at $\mathrm{OD}_{620} 1 \cdot 0$ is shown in Fig. 1. RpoS amounts were severely reduced as a result of mutations in $p s r A$ (PCL1111, lane 3) and gacS (PCL1123, lane 5). Mutations in phzI (PCL1103, lane 2) and in phzB (PCL1119, lane 4) did not affect the production of RpoS.

\section{Relationship between psrA, rpoS and gacS}

A psrA mutant of PCL1391 showed low production of PCN and $\mathrm{N}$-AHL when grown in MVB1 medium as compared to
PCL1391 (decrease of 99\%) (Figs 2c and 3a). It was shown that $p s r A$ regulates $r p o S$ in other Pseudomonas species (Kojic \& Venturi 2001), probably via binding to the promoter of the rpoS gene at a PsrA-binding box. Therefore, an attempt was made to complement the psrA mutant PCL1111 with constitutively expressed rpoS. For this purpose, the vector pMP7420 ( $\mathrm{P}_{\text {tac }}$ rpoS) was transformed into PCL1111, which resulted in PCL1961. PCL1961 showed increased PCN and $\mathrm{N}$-AHL levels compared to the psrA mutant and produced up to $55 \%$ of the amount of PCN produced by the wildtype (Figs 2c and 3a). PCL 2048, the rpoS mutant overexpressing $p s r A$, was unable to produce PCN (Fig. 2b) or $\mathrm{N}$ AHL (Fig. 3c). As a control, we transformed pMP7465 (pBBR1MCS-5 harbouring $\mathrm{P}_{t a c} p s r A$ ) into PCL1111 ( $p s r A$ ). The resulting strain, PCL2045, showed restored levels of PCN and $\mathrm{C}_{6}$-HSL (Figs $2 \mathrm{c}$ and $3 \mathrm{c}$ ). Constitutive expression of $p h z R$ also restored production of PCN and N-AHL in a psrA background (strain PCL1996, Figs 2c and 3b). 
Since it was shown that $\mathrm{GacA} / \mathrm{GacS}$ regulate $\mathrm{PCN}$ and $\mathrm{N}$ AHL production in $\mathrm{KB}$ medium, as well as $p s r A$ expression (Chin-A-Woeng et al., 2005), and that RpoS is severely decreased in the gacS mutant PCL1123, the relationship between GacS, PsrA/RpoS, quorum sensing and PCN was studied in more detail. The gacS mutant did not produce any detectable PCN or N-AHL in MBV1 (Figs 2d and 3d). Neither constitutive $r p o S$ expression, nor constitutive expression of psrA (Figs $2 \mathrm{~d}$ and $3 \mathrm{~d}$ ), was sufficient to compensate for the gacS mutation. Only the constitutive phzR gene restored PCN and AHL production in a gacS mutated background (Figs $2 \mathrm{~d}$ and $3 \mathrm{~d}$ ). Surprisingly, after overnight growth (see Figure 1 in the supplementary materials available at http://rulbim.leidenuniv.nl/girard/suppl material.htm), high amounts of PCA are present in strains PCL1986 and PCL1998 (rpoS and gacS mutant, respectively, both overexpressing phzR), but not in PCL1993 or PCL1996 (wild-type and psrA mutant, respectively, both overexpressing $p h z R)$.

\section{Transcriptomics in psrA and rpos mutants: a preliminary survey}

In order to evaluate the pathways regulated by $p s r A$ and $r p o S$, the gene expression profiles of psrA (PCL1111) and rpoS (PCL1954) were compared with the gene expression of wild-type PCL1391 on microarrays. As an example for the reader and in order to comply with the MIAME standards (Brazma et al., 2001), one representative experiment among four, for both sets of microarrays, was selected for each mutant and the corresponding data, i.e. images, raw output of image analysis, normalized and flagged data, are available at http://rulbim.leidenuniv.nl/girard/suppl material.htm. The data filter (see Methods for details of the filtering of the data) selected in total 190 spots for the experiments with the $p s r A$ mutant, of which 157 had a stronger intensity in the wild-type, and 33 a lower intensity. Two hundred and thirty-four spots were selected from the experiments involving the rpoS mutant, of which 211 had a strong intensity in the wild-type, and 23 a lower intensity. A total of 108 spots were common to the group of 190 spots from $p s r A$ arrays and the group of 234 spots from rpoS arrays. They were all more intense in the wild-type than in the psrA and rpoS mutants. Among these 108 spots, the 57 spots that were most strongly affected by both mutations were selected and the corresponding DNA was sequenced. The sequences of the clones are also available at http://rulbim.leidenuniv.nl/ girard/suppl material.htm. The analysis of sequences and the variations of expression due to $r p o S$ and $p s r A$ mutations are presented in Table 3. The clones were grouped according to the predicted function of the ORF in the insert.

The microarray data reveal that the expression of phz biosynthetic genes is decreased at least sevenfold in the rpoS mutant PCL1954 and around 15-fold in the psrA mutant PCL1111 (clones 4_D1, 119_D12 and 126_G12 in Table 3, and controls shown in the supplementary material). In addition, some clones sequenced after microarray analysis containing parts of the $p h z I / p h z R$ genes (24_C5 and
93_G11) have decreased expression around fivefold in the psrA mutant and around sevenfold in the rpoS mutant.

Sequencing of 19 selected clones and homology studies identified the presence of hypothetical proteins. On several clones, two or three ORFs could be identified since the microarrays were constructed from a library of random PCL1391 chromosomal fragments of approximately 1 to $2 \mathrm{~kb}$. Additional RT-PCR experiments should be performed to show which gene or operon is responsible for the ratio measured. For most genes, it was observed that they correspond to homologues that are also adjacent to each other in other sequenced Pseudomonas genomes. Several genes were sequenced that give homology to genes which cannot be obviously linked to $r p o S$ and $p s r A$ functions, like an aminotransferase (clone 4_G11), or a deoxycytidylate deaminase (clone 4_C1) and a putative adhesin (Pflu3629) which is recurrent in the clones. However, many clones (12) show homology to genes that could be related to intermediary and secondary metabolism (see Table 3 ). Other interesting clones (4) show homology to regulators.

In order to test several of the genes that were selected by microarray analyses, three mutants were constructed. (i) PCL2009 is mutated in a putative transcriptional regulator gene identified in microarray clone 76_G2. (ii) PCL2050 is mutated in a putative GGDEF/EAL regulator identified in microarray clone 42_G8. (iii) PCL2052 is mutated in a hypothetical protein identified in microarray clones 76_G2 and 47_F5. Various phenotypic traits of these mutants were analysed (see Methods). The mutants showed wild-type production of $\mathrm{HCN}$, chitinase and exoprotease. They were all able to swim and swarm, although PCL2052 showed decreased swimming ability and PCL2050 seemed to be also affected in its swarming (not shown). The $\mathrm{PCN}$ production of PCL2009 $(465 \pm 28 \mu \mathrm{M})$ and PCL2052 $(435 \pm 14 \mu \mathrm{M})$ appeared to be increased twofold compared to PCL1391 $(237 \pm 9 \mu \mathrm{M})$.

\section{DISCUSSION}

\section{psrA and rpoS control PCN production in $P$. chlororaphis PCL1391}

The organization of the rpoS gene in strain PCL1391 is comparable to that observed in other pseudomonads (Fujita et al., 1994; Heeb \& Haas, 2001; Kojic et al., 1999, 2002; Ramos-González \& Molin, 1998). A substantial difference is the presence of a putative transposase downstream of $r p o S$ in PCL1391, whereas in many other Pseudomonas spp. rpoS is followed by $r s m Z$ and the ferredoxin gene $f d x A$ (Heurlier et al., 2004). No indication could be found of the presence of an $r s m Z$ gene downstream of $r p o S$ in PCL1391. Measurements of the production of PCN and N-AHL in various derivatives (Figs 2 and 3) show that rpoS activates the synthesis of these two metabolites.

This study was started with the assumption that $p s r A$ and rpoS would constitute two components of a cascade 
Table 3. Genes whose expression was identified as being regulated by $r p o S$ and $p s r A$ by using microarrays

\begin{tabular}{|c|c|c|c|c|c|}
\hline Clone no.* & $\begin{array}{c}\text { Change of } \\
\text { expression in } \\
\text { PCL1111 }(p s r A) \dagger\end{array}$ & $\begin{array}{c}\text { Change of } \\
\text { expression in } \\
\text { PCL1954 }(r p o S) \dagger\end{array}$ & $\begin{array}{l}\text { Gene homology } \\
\text { and/or } \\
\text { accession no. } \ddagger\end{array}$ & $\begin{array}{c}\text { Bacterium } \\
\text { corresponding to the } \\
\text { gene homology } \S\end{array}$ & Predicted functionll \\
\hline \multicolumn{6}{|l|}{ phz genes } \\
\hline 2_A5 & $20 \cdot 2 \pm 5 \cdot 69$ & $13 \cdot 9 \pm 3 \cdot 15$ & $p h z R(\mathrm{AAF} 17494)$ & P. chlororaphis & Transcriptional activator \\
\hline 93_G11 & $6 \cdot 00 \pm 1 \cdot 95$ & $8 \cdot 27 \pm 2 \cdot 30$ & phzI (AAF17493) & P. chlororaphis & Autoinducer synthase \\
\hline 24_C5 & $3 \cdot 76 \pm 0 \cdot 659$ & $6 \cdot 13 \pm 0 \cdot 803$ & $\begin{array}{l}\text { phzI (AAF17493) and } \\
p h z R(\mathrm{AAF} 17494)\end{array}$ & P. chlororaphis & Autoinducer synthase and transcriptional activator \\
\hline 4_D1 & $21 \cdot 2 \pm 8 \cdot 40$ & $12 \cdot 2 \pm 0 \cdot 794$ & $\begin{array}{l}p h z B / C(\mathrm{AAF} 17496 \\
\text { and AAF17497) }\end{array}$ & P. chlororaphis & Biosynthetic genes for PCN \\
\hline 97_D1 & $29 \cdot 1 \pm 5 \cdot 38$ & $18 \cdot 0 \pm 2 \cdot 59$ & phzD (AAF17498) & P. chlororaphis & Biosynthetic gene for PCN \\
\hline 119_D12 & $10 \cdot 1 \pm 2 \cdot 97$ & $7 \cdot 21 \pm 1 \cdot 44$ & phzE (AAF17499) & P. chlororaphis & Biosynthetic gene for PCN \\
\hline 126_G12 & $14 \cdot 6 \pm 4 \cdot 01$ & $9 \cdot 22 \pm 2 \cdot 27$ & $p h z H($ AAF17502) & P. chlororaphis & Biosynthetic gene for PCN \\
\hline \multicolumn{6}{|c|}{ Membrane protein genes } \\
\hline 2_C4 & $3 \cdot 63 \pm 0 \cdot 444$ & $10 \cdot 9 \pm 3 \cdot 49$ & ZP_00262806 & P. fluorescens & Autotransporter adhesin \\
\hline 13_B1 & $3 \cdot 77 \pm 0 \cdot 507$ & $9 \cdot 16 \pm 1 \cdot 57$ & ZP_00262806 & P. fluorescens & Autotransporter adhesin \\
\hline 36_A12 & $3 \cdot 32 \pm 0 \cdot 386$ & $7 \cdot 62 \pm 1 \cdot 656$ & ZP_00262806 & P. fluorescens & Autotransporter adhesin \\
\hline 38_G7 & $3 \cdot 39 \pm 0 \cdot 296$ & $8 \cdot 04 \pm 1 \cdot 70$ & ZP_00262806 & P. fluorescens & Autotransporter adhesin \\
\hline 105_A12 & $3 \cdot 57 \pm 0 \cdot 238$ & $7 \cdot 95 \pm 1 \cdot 72$ & ZP_00262806 & P. fluorescens & Autotransporter adhesin \\
\hline 115_A2 & $3 \cdot 10 \pm 0 \cdot 427$ & $4 \cdot 98 \pm 1 \cdot 03$ & $\begin{array}{l}\text { ZP_00263190 and } \\
\text { NP_745085 }\end{array}$ & $\begin{array}{l}\text { P. fluorescens and } \\
\text { P. putida }\end{array}$ & $\begin{array}{l}\text { Integral membrane protein }(1-59 / 223) \text { and conserved } \\
\text { hypothetical protein }(169-253 / 261)\end{array}$ \\
\hline 4_H7 & $4 \cdot 71 \pm 0 \cdot 669$ & $2 \cdot 23 \pm 0 \cdot 290$ & $n l p D(\mathrm{AAP} 97085)$ & P. chlororaphis & Lipoprotein $(86-265 / 294)$ \\
\hline \multicolumn{6}{|c|}{ Primary metabolism genes } \\
\hline 4_C1 & $4 \cdot 11 \pm 0 \cdot 695$ & $3 \cdot 77 \pm 1 \cdot 66$ & NP_762166 & V. vulnificus & Deoxycytidylate deaminase (139-514/622) \\
\hline 4_G11 & $4 \cdot 93 \pm 1 \cdot 77$ & $7 \cdot 39 \pm 3 \cdot 58$ & NP_901074 & C. violaceum & Aminotransferase (4-268/367) \\
\hline \multicolumn{6}{|c|}{ Intermediary metabolism genes } \\
\hline 2_B3 & $3 \cdot 45 \pm 0 \cdot 684$ & $7 \cdot 36 \pm 1 \cdot 17$ & phaC2 (BAB78721) & P. chlororaphis & PHA synthase $2(225-560 / 560)$ \\
\hline 41_G2 & $3 \cdot 28 \pm 0 \cdot 741$ & $7 \cdot 19 \pm 1 \cdot 82$ & phaC2 (BAB78721) & P. chlororaphis & PHA synthase $2(1-376 / 560)$ \\
\hline 53_F2 & $2 \cdot 89 \pm 1 \cdot 01$ & $5 \cdot 05 \pm 0 \cdot 785$ & phaG (BAB32432) & Pseudomonas sp. 61-3 & $\begin{array}{l}\text { 3-Hydroxyacyl-acyl carrier protein CoA transferase } \\
(131-294 / 294)\end{array}$ \\
\hline 60_E1 & $2 \cdot 85 \pm 0 \cdot 924$ & $4 \cdot 91 \pm 0 \cdot 901$ & Clone identical to 53_F2 & Pseudomonas sp. 61-3 & Clone identical to 53_F2 \\
\hline 71_A4 & $2 \cdot 40 \pm 0 \cdot 313$ & $4 \cdot 29 \pm 0 \cdot 592$ & Clone identical to 53_F2 & Pseudomonas sp. 61-3 & Clone identical to 53_F2 \\
\hline 74_B4 & $2 \cdot 75 \pm 0 \cdot 632$ & $5 \cdot 29 \pm 1 \cdot 01$ & Clone identical to 53_F2 & Pseudomonas sp. $61-3$ & Clone identical to 53_F2 \\
\hline 74_E7 & $2 \cdot 74 \pm 0 \cdot 548$ & $5 \cdot 19 \pm 1 \cdot 82$ & Clone identical to 53_F2 & Pseudomonas sp. $61-3$ & Clone identical to 53_F2 \\
\hline 93_D8 & $2 \cdot 50 \pm 0 \cdot 507$ & $6 \cdot 26 \pm 1 \cdot 847$ & phaG (BAB32432) & Pseudomonas sp. $61-3$ & $\begin{array}{l}\text { 3-Hydroxyacyl-acyl carrier protein CoA transferase } \\
(124-294 / 294)\end{array}$ \\
\hline \multicolumn{6}{|c|}{ Secondary metabolism genes } \\
\hline 11_G8 & $4 \cdot 00 \pm 0 \cdot 500$ & $5 \cdot 68 \pm 1 \cdot 39$ & chiC (NP_250990) & P. aeruginosa & Chitinase (293-373/483) \\
\hline 121_H3 & $3 \cdot 15 \pm 0 \cdot 320$ & $6 \cdot 27 \pm 0 \cdot 768$ & chiC (NP_250990) & P. aeruginosa & Chitinase (165-479/483) \\
\hline
\end{tabular}


Table 3. cont.

\begin{tabular}{|c|c|c|c|c|c|}
\hline Clone no.* & $\begin{array}{c}\text { Change of } \\
\text { expression in } \\
\text { PCL1111 }(p s r A) \dagger\end{array}$ & $\begin{array}{c}\text { Change of } \\
\text { expression in } \\
\text { PCL1954 }(r p o S) \dagger\end{array}$ & $\begin{array}{l}\text { Gene homology } \\
\text { and/or } \\
\text { accession no. }\end{array}$ & $\begin{array}{l}\text { Bacterium } \\
\text { corresponding to the } \\
\text { gene homology } \S\end{array}$ & Predicted functionll \\
\hline 100_B7 & $3 \cdot 36 \pm 0 \cdot 399$ & $7 \cdot 41 \pm 0 \cdot 574$ & NP_746359 & P. putida & Pyoverdine synthase? (665-987/4317) \\
\hline 86_H8 & $5 \cdot 93 \pm 3 \cdot 87$ & $10 \cdot 4 \pm 0 \cdot 836$ & $\begin{array}{l}\text { NP_901071 and } \\
\text { NP_901070 }\end{array}$ & C. violaceum & $\begin{array}{l}\text { Probable dihydrorhizobitoxine desaturase }(248-353 / 369) \\
\text { and probable } 5^{\prime} \text {-methylthioadenosine phosphorylase } \\
(31-186 / 302)\end{array}$ \\
\hline \multicolumn{6}{|c|}{ Regulatory genes } \\
\hline 65_B7 & $5 \cdot 20 \pm 0 \cdot 747$ & $2 \cdot 89 \pm 0 \cdot 321$ & $\begin{array}{l}r p o S \text { (AAP97086) and } \\
n l p D \text { (AAP97085) }\end{array}$ & P. chlororaphis & $\begin{array}{l}\text { RNA polymerase sigma factor }(1-155 / 334) \text { and } \\
\text { lipoprotein }(96-294 / 294)\end{array}$ \\
\hline 98_B2 & $5 \cdot 94 \pm 0 \cdot 511$ & $3 \cdot 06 \pm 0 \cdot 405$ & rpoS (AAP97086) & P. chlororaphis & RNA polymerase sigma factor $(40-334 / 334)$ \\
\hline 42_G8 & $3 \cdot 77 \pm 0 \cdot 958$ & $7 \cdot 22 \pm 1 \cdot 73$ & ZP_00264029 & P. fluorescens & $\begin{array}{l}\text { GGDEF/EAL domains containing regulator } \\
(260-617 / 624)\end{array}$ \\
\hline 76_G2 & $3 \cdot 37 \pm 0 \cdot 916$ & $4 \cdot 38 \pm 1 \cdot 32$ & $\begin{array}{l}\text { ZP_00263882 and } \\
\text { ZP_00263883 }\end{array}$ & P. fluorescens & $\begin{array}{l}\text { Hypothetical protein }(378-454 / 454) \text { and } \\
\text { ATP-dependent transcriptional regulator }(1-236 / 911)\end{array}$ \\
\hline \multicolumn{6}{|c|}{ Hypothetical protein genes } \\
\hline 72_D12 & $7 \cdot 48 \pm 2 \cdot 188$ & $40 \cdot 1 \pm 12 \cdot 2$ & $\begin{array}{l}\text { ZP_00262803, ZP_00262802 } \\
\text { and ZP_00262796 }\end{array}$ & P. fluorescens & $\begin{array}{l}\text { Microcystin-dependent protein }(1-191 / 191) \text {, } \\
\text { hypothetical protein }(1-103 / 103) \text { and histone } \\
\text { acetyltransferase }(71-161 / 163)\end{array}$ \\
\hline 119_A8 & $7 \cdot 46 \pm 1 \cdot 16$ & $31 \cdot 8 \pm 5 \cdot 42$ & $\begin{array}{l}\text { ZP_00262803 and } \\
\text { ZP_00262802 }\end{array}$ & P. fluorescens & $\begin{array}{l}\text { Microcystin-dependent protein }(1-191 / 191) \text { and } \\
\text { hypothetical protein }(1-92 / 103)\end{array}$ \\
\hline 1_B9 & $3 \cdot 28 \pm 0 \cdot 573$ & $5 \cdot 05 \pm 1 \cdot 05$ & ZP_00266535 & P. fluorescens & Hypothetical protein $(58-170 / 170)$ \\
\hline 3_F11 & $3 \cdot 20 \pm 0 \cdot 882$ & $4 \cdot 33 \pm 0 \cdot 417$ & ZP_00128106 & P. syringae pv. syringae & Hypothetical protein $(31-170 / 170)$ \\
\hline 11_E2 & $3 \cdot 39 \pm 0 \cdot 469$ & $4 \cdot 75 \pm 0 \cdot 522$ & $\begin{array}{l}\text { ZP_00263881.1 and } \\
\text { ZP_00263880 }\end{array}$ & P. fluorescens & $\begin{array}{l}\text { Hypothetical protein }(1-184 / 629) \text { and acyl-CoA } \\
\text { synthetases (AMP-forming)/AMP-acid ligases II } \\
(528-551 / 560)\end{array}$ \\
\hline 21_E2 & $2 \cdot 80 \pm 0 \cdot 621$ & $3 \cdot 96 \pm 0 \cdot 278$ & Clone identical to 11_E2 & P. fluorescens & Clone identical to 11_E2 \\
\hline 12_G9 & $3 \cdot 75 \pm 0 \cdot 831$ & $6 \cdot 30 \pm 1 \cdot 68$ & PP2941 (NP_745085) & P. putida & Conserved hypothetical protein (187-253/261) \\
\hline 41_A12 & $5 \cdot 56 \pm 2 \cdot 02$ & $11 \cdot 5 \pm 1 \cdot 66$ & $\begin{array}{l}\text { ZP_00262372 and } \\
\text { ZP_00262371 }\end{array}$ & P. fluorescens & $\begin{array}{l}\text { Uncharacterized conserved protein }(1-153 / 423) \text { and } \\
\text { putative Ser protein kinase }(525-640 / 640)\end{array}$ \\
\hline 47_F5 & $4 \cdot 46 \pm 0 \cdot 668$ & $7 \cdot 59 \pm 3 \cdot 30$ & $\begin{array}{l}\text { ZP_00263881 and } \\
\text { ZP_00263882 }\end{array}$ & P. fluorescens & $\begin{array}{l}\text { Hypothetical protein }(524-629 / 629) \text { and hypothetical } \\
\text { protein }(1-335 / 454)\end{array}$ \\
\hline 72_H6 & $4 \cdot 65 \pm 1 \cdot 17$ & $7 \cdot 02 \pm 2 \cdot 08$ & Clone identical to $47 \_$F5 & P. fluorescens & Clone identical to $47 \_$F5 \\
\hline 93_H9 & $4 \cdot 11 \pm 0 \cdot 385$ & $5 \cdot 27 \pm 0 \cdot 557$ & Clone identical to 47_F5 & P. fluorescens & Clone identical to 47_F5 \\
\hline 112_C1 & $3 \cdot 95 \pm 0 \cdot 386$ & $5 \cdot 77 \pm 0 \cdot 457$ & Clone identical to $47 \_F 5$ & P. fluorescens & Clone identical to $47 \_F 5$ \\
\hline 59_C10 & $3 \cdot 67 \pm 0 \cdot 508$ & $3 \cdot 70 \pm 0 \cdot 614$ & NP_929618 & $\begin{array}{l}\text { Ph. luminescens subsp. } \\
\text { laumondii }\end{array}$ & Hypothetical protein (2-93/93) \\
\hline
\end{tabular}


Table 3. cont.

\begin{tabular}{|c|c|c|c|c|c|}
\hline Clone no.* & $\begin{array}{c}\text { Change of } \\
\text { expression in } \\
\text { PCL1111 }(p s r A) \dagger\end{array}$ & $\begin{array}{c}\text { Change of } \\
\text { expression in } \\
\text { PCL1954 }(r p o S) \dagger\end{array}$ & $\begin{array}{c}\text { Gene homology } \\
\text { and/or } \\
\text { accession no. } \ddagger\end{array}$ & $\begin{array}{l}\text { Bacterium } \\
\text { corresponding to the } \\
\text { gene homology } \S\end{array}$ & Predicted functionll \\
\hline 65_H9 & $3 \cdot 67 \pm 1 \cdot 30$ & $8 \cdot 22 \pm 2 \cdot 40$ & $\begin{array}{l}\text { ZP_00267318 and } \\
\text { ZP_00266917 }\end{array}$ & P. fluorescens & $\begin{array}{l}\text { RTX toxin and related } \mathrm{Ca}^{2+} \text {-binding protein } \\
(428-468 / 468) \text { and hypothetical protein }(34-248 / 300)\end{array}$ \\
\hline 74_H8 & $6 \cdot 88 \pm 1 \cdot 11$ & $25 \cdot 3 \pm 4 \cdot 08$ & NP_929844 & $\begin{array}{l}\text { Ph. luminescens subsp. } \\
\text { laumondii }\end{array}$ & Hypothetical protein (12-281/325) \\
\hline 81_G2 & $3 \cdot 76 \pm 1 \cdot 09$ & $7 \cdot 07 \pm 1 \cdot 92$ & ZP_00128106 & P. syringae pv. syringae & Hypothetical protein $(58-170 / 170)$ \\
\hline 119_C6 & $2 \cdot 91 \pm 0 \cdot 441$ & $4 \cdot 18 \pm 0 \cdot 963$ & & & No homology \\
\hline
\end{tabular}

${ }^{\star}$ The clone number refers to the number in the library (plate number, row and column).

$\dagger$ All the spots selected in this table corresponded to genes of which the expression was lower in the mutant than in the wild-type. Thus the ratios represent the intensity of the spots in the wildtype over the intensity in the mutant.

¥Because the microarray was spotted from a random genomic library, some clones appeared to be spotted several times. In this case, it is indicated in the last column ("clone identical to"). \$Genus abbreviations: C., Chromobacterium; P., Pseudomonas; Ph., Photorhabdus; V., Vibrio. The precise strains are: P. chlororaphis strain 06, except for the phz genes, which are from strain PCL1391, and phaC2, which is homologous to phaC2 of strain IFO 3521; P. fluorescens PfO1; P. putida KT2440; P. aeruginosa PAO1; P. syringae pv. syringae B728a; V. vulnificus CMCP6; C. violaceum ATCC 12472; and Ph. luminescens subsp. laumondii TTO1.

IIn parentheses, the region of the protein encoded on the insert of the clone is indicated (first amino acid-last amino acid/total amino acid length). 
regulating the phz operon, according to results in other strains (Kojic \& Venturi, 2001). Previous work in rich growth medium indicated that PsrA inhibits $N$-AHL and PCN production in PCL1391 (Chin-A-Woeng et al., 2005). In our study using the poor MVB1 medium, psrA was shown to activate PCN and N-AHL production in PCL1391. The microarray data from cells grown in MVB1 medium confirmed that the expression of the phz genes is strongly reduced by the psrA and rpoS mutations (Table 3). Constitutively expressed rpoS strongly increased PCN and $N$ AHL production in a psrA mutant (strain PCL1961, Figs 2c and $3 \mathrm{a}$ ). The fact that the complementation was only partial (also in the rpoS mutant) could be explained by two hypotheses. (i) PsrA regulates other genes not downstream of $r p o S$ that are necessary for full activation of the phz genes. (ii) A fine-tuning of rpoS expression might be necessary for wild-type amounts of PCN, which is not possible when the gene is under the control of a constitutive promoter. It was previously shown for $P$. putida that PsrA regulates the expression of rpoS (Kojic \& Venturi, 2001) by binding to its promoter (Kojic et al., 2002). Our results indicate a similar regulation in PCL1391. Our results show to our knowledge for the first time that this interaction is relevant for a particular phenotypic trait, the production of the secondary metabolite PCN.

Interestingly, our results show that the effect of a psrA mutation is dependent on the growth conditions. Additionally, it is remarkable that constitutive expression of rpoS does not restore PCN production in $r p o S$ and $p s r A$ mutants to the same level in cultures grown in different volumes of medium (Figs 2 and 3). Although this looks peculiar, it is not unique, since conditional results were also reported for another phenazine regulator, RpeA (repressor of phenazine expression) (Whistler \& Pierson, 2003). RpeA was shown to regulate PCN production mostly in minimal medium, not in complex medium. Similarly, RpoS could have a role in controlling secondary metabolism mostly under nutrientlimiting conditions. It could act as a controller of energy distribution in the cell when the nutritional conditions are more stringent, as indicated by the high sensitivity to external conditions of the strains constitutively expressing rpoS (see also below). It is also likely that other unidentified factors sensing environmental changes are involved in PCN regulation; this could explain the switch in the role of PsrA between KB medium and MVB1 medium. Conditions in the soil are known to be nutrient-limiting. Therefore the choice of a relatively poor medium as MVB1 seemed more relevant for this study.

\section{A regulation cascade between gacS and the phz operon involves psrA, rpos and the quorum-sensing system phzl/phzR}

Under various growth conditions the amounts of $\mathrm{C}_{6}-\mathrm{HSL}$ present in PCL1391 spent culture medium were shown to be correlated with the amounts of PCN produced (ChinA-Woeng et al., 2001b, 2003; van Rij et al., 2004). In our study, the correlation of PCN and $\mathrm{C}_{6}$-HSL levels among the various PCL1391 derivatives (Fig. 3) and the restoration of PCN production by constitutive $p h z R$ expression in the $r p o S$ and psrA mutants (Fig. 2b, c) show that rpoS stimulates PCN production via $p h z I / p h z R$. Conversely, $p h z I$ does not regulate rpoS expression (Fig. 1). A role of $r p o S$ in antibiotic production has been reported (Sarniguet et al., 1995; Suh et al., 1999), but not for regulating PCN production. The inhibitory effect of RpoS on quorum sensing and pyocyanin in P. aeruginosa (Whiteley et al., 2000) or of PsrA and RpoS on quorum sensing in P. putida WCS358 (Bertani \& Venturi, 2004) is the opposite of what we observed for strain PCL1391. Surprisingly, RpoS was previously shown not to be involved in homoserine lactone production by $P$. putida WCS358 (Kojic et al., 1999). This is interesting for our study, because in the latter case $P$. putida was grown in minimal medium (Kojic et al., 1999), whereas in the most recent study $P$. putida was grown in the complex LB medium (Bertani \& Venturi, 2004). In P. aeruginosa, the effect of quorum sensing on rpoS transcription in $P$. aeruginosa is mild (Schuster et al., 2004). Thus, very diverse relationships exist between PsrA/RpoS and quorum sensing/antibiotic production depending on the bacterial species, and on environmental conditions for any one species.

Western blot analysis showed that a mutation in $p h z B$ does not affect the RpoS level, which suggests that there is no feedback effect from $\mathrm{PCN}$ production on rpoS expression. A defect in the regulatory genes $p s r A$ or gacS results in a severe decrease of the amounts of RpoS. Similar observations were made in other strains (Kojic \& Venturi, 2001; SchmidtEisenlohr et al., 2003; Whistler et al., 1998).

Our data confirm the key role of gacS for PCN synthesis (Fig. 2d). Constitutive rpoS expression did not restore PCN synthesis in a gacS mutant (PCL2010), which indicates that as well as rpoS in the regulatory cascade, other factors affected by gacS are necessary for PCN production (Fig. 4). However, constitutive expression of the $p h z R$ gene restores PCN and N-AHL synthesis in a gacS mutant (PCL1998). This could be surprising considering that in $P$. aureofaciens 30-84, which is closely related to P. chlororaphis PCL1391, GacS/GacA affect mostly the transcription of phzI and not that of $p h z R$ (Chancey et al., 1999). Additionally, phenazine synthesis is regulated in a comparable way in both strains by PhzI/PhzR/C 6 -HSL and GacS/GacA (Chancey et al., 1999; Pierson et al., 1994; Wood et al., 1997; Wood \& Pierson, 1996). The role of PsrA and RpoS in phenazine synthesis has so far not been studied in strain $30-84$. The following hypothesis would reconcile the results in both strains: GacS/GacA could regulate phzI at the transcriptional level and $p h z R$ at the post-transcriptional level, since it was shown that GacA acts at both levels (Blumer et al., 1999; Pessi \& Haas, 2001). In our gacS mutant, the presence of constitutively expressed $p h z R$ would result in an excess of PhzR mRNA that would overcome negative posttranscriptional regulation. The PhzR protein produced in turn would bind the low amounts of $\mathrm{C}_{6}$-HSL resulting from leakage of the phzI promoter and restart the positive 


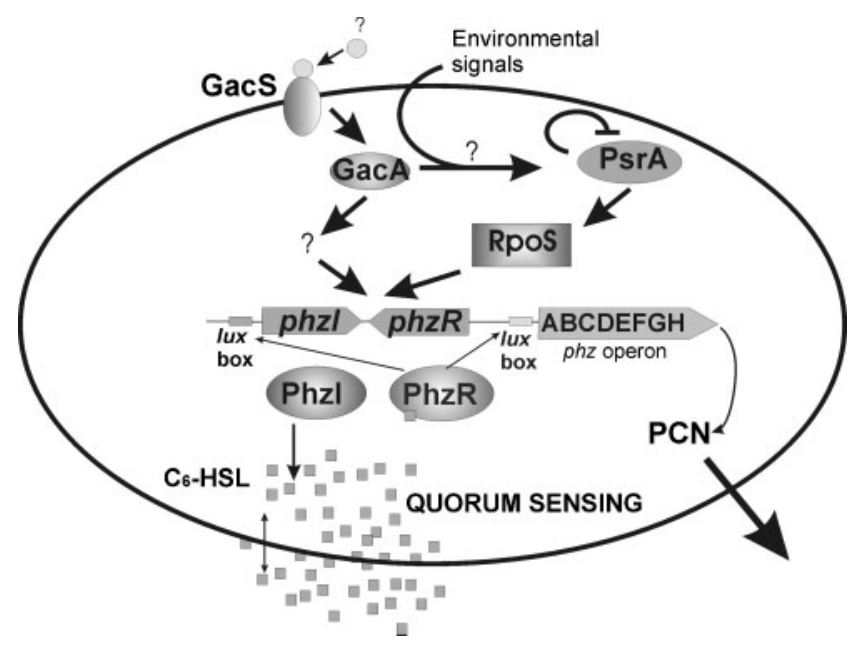

Fig. 4. Model for the regulatory cascade governing $P C N$ production in $P$. chlororaphis PCL1391 in MVB1 medium. Upstream in the cascade, the sensor GacS is activated by a putative environmental factor. Subsequently, GacS stimulates its cognate kinase GacA. GacA activates a cascade of genes including PsrA and RpoS. As well as GacA, unknown environmental factors probably affect PsrA. This part of the regulation is so far not understood. In a second cascade, unknown factors are regulated by GacA. These unknown factors, together with RpoS, activate the quorum-sensing system phzl/phzR, which in turn switches on expression of the phz operon. The phz operon is responsible for the synthesis of PCN.

regulatory loop of PhzI/PhzR by binding to the lux box upstream of phzI. It would be of great interest to test if a constitutive expression of $p h z R$ could restore phenazine production in a gacS mutant of strain 30-84.

Restoration of PCN and $\mathrm{C}_{6}$-HSL production by constitutive expression of $p h z R$ in all the tested mutants is very striking and indicates that for expression of the phz operon, a functional expressed quorum-sensing system is sufficient. However, it is surprising that after overnight growth, overexpression of $p h z R$ induces high amounts of PCA only in rpoS and gacS mutants (see Figure 1 in the supplementary material available at http://rulbim.leidenuniv.nl/girard/suppl material.htm). Conversely, only PCL1993 and PCL1996 (wild-type and $p s r A$ mutant, respectively, both overexpressing $p h z R$ ) show a peak of PCN production (Fig. 2a, c). These observations could be explained by precipitation of $\mathrm{PCN}$, indicated by the presence of numerous crystals in overnight cultures observed only in the case of PCL1993 and PCL1996. Since there is still a low amount of RpoS present in the $p s r A$ mutant (Fig. 1), an explanation for the high production of PCA could be that rpoS regulates (probably indirectly) the $p h z H$ gene, responsible for the conversion of PCA to PCN. The phzH gene is the last gene of the $p h z$ operon in PCL1391. It is remarkable that the distances between the phz genes phzA, B, $C, D, E, F$ and $G$ do not exceed $15 \mathrm{nt}$, whereas there are $111 \mathrm{nt}$ between $p h z G$ and phzH (Chin-A-Woeng et al., 2001a), which could provide a binding site for regulatory proteins. Various computer analyses did not point to any particular sequence within these $111 \mathrm{nt}$.

\section{Transcriptome analyses of psrA and rpos mutants of $P$. chlororaphis PCL1391}

Functional genomics provides a high-throughput analysis possibility to identify the genes of the cascade downstream of rpoS. However, the expected large amount of genes due to very downstream effects of $r p o S$ would hamper the selection of genes of interest. $r p o S$ and $p s r A$ are predicted to be close to each other in the regulatory cascade for PCN synthesis. Therefore the data of microarray analyses of $p s r A$ and $r p o S$ were crossed. This approach increases the probability of selecting genes which are part of the $p s r A / r p o S$ regulatory cascade.

Our selection method revealed 13 clones containing parts of genes from the $p h z$ operon and $p h z$ quorum-sensing system (not all of them are shown in Table 3 for conciseness), which strongly validates our method. Besides, many of the genes sequenced from the positive clones were also present on other selected clones spotted elsewhere on the microarray (like phaG in clones 53_F2, 60_E1, 71_A4, 74_B4, 74_E7 or chiC in clones 11_G8 and 121_H3). These observations contribute to the validation of our microarray analyses.

Many clones carry genes that show homology to genes related to intermediary and secondary metabolism, such as phaC2, phaG, chiC, pyoverdine synthase and a probable dihydrorhizobitoxine desaturase (Table 3). phaC2 was reported to be involved in polyhydroxyalkanoic acid (PHA) synthesis (Nishikawa et al., 2002; Qi et al., 1997). phaG is also involved in PHA synthesis (Rehm et al., 1998). PHAs are polymers used for carbon and energy storage in bacteria in response to environmental stress, which would explain their regulation by rpoS. chiC encoding a chitinase was shown to be regulated by quorum sensing in $P$. aeruginosa PAO1 (Folders et al., 2001).

One clone (76_G2) contains a putative regulatory gene with a HTH-LuxR domain (SMART accession SM00421) and therefore might respond to N-AHLs. A mutation in this regulator, as well as in the hypothetical protein upstream of it, resulted in a twofold increase in PCN production. The function of these genes has to our knowledge not yet been characterized in other strains. Our data show that these genes affect PCN production in strain PCL1391. The third gene of interest located on clone 42_G8 contains GGDEF and EAL domains, which are found in two-component signalling systems (Galperin et al., 2001). A recent study shows the involvement of such a protein (RocS) in regulation of the rugose phenotype and biofilm formation in Vibrio cholerae (Rashid et al., 2003). A mutation in this putative regulatory gene did not change PCN production.

Our results show that a cascade involving GacS/GacA, PsrA, RpoS and quorum sensing regulates the phz operon and 
that several regulators downstream of GacS/GacA must exist in addition to PsrA/RpoS to activate expression of the $p h z$ operon. Preliminary microarray analyses, by allowing measurement of the effect of $p s r A$ and rpoS mutations on the $p h z$ genes, support our model of the regulation of PCN production. In addition, these data led to the identification of novel genes involved in regulatory fine-tuning of PCN production. The microarray analyses form a solid basis for future studies on identifying the role of other novel genes and their relation to $p s r A, r p o S$ and secondary metabolism, particularly PCN production.

\section{ACKNOWLEDGEMENTS}

The authors thank K. Tanaka (Institute of Molecular and Cellular Biosciences, University of Tokyo, Japan) for providing the anti-RpoS rabbit serum and Naomi Kramer (RUG, Groningen, the Netherlands), Joanna Cardoso, Ellen Sterrenburg, Rolf Turk and André Wijfes (LGTC, Leiden, the Netherlands) for technical advice concerning microarray. This project was financially supported by the FW6 EU R\&D project QRLT-2002-00914 (acronym 'Pseudomics'). G. Girard was financially supported by the BioScience Initiative from Leiden University.

\section{REFERENCES}

Ausubel, F. M., Brent, R., Kingston, R. E., Moore, D. D., Seidman, J. G., Smith, J. A. \& Struhl, K. (1997). Current Protocols in Molecular Biology. New York: Wiley.

Bakker, P. A., Glandorf, D. C., Viebahn, M. \& 7 other authors (2002). Effects of Pseudomonas putida modified to produce phenazine1-carboxylic acid and 2,4-diacetylphloroglucinol on the microflora of field grown wheat. Antonie Van Leeuwenhoek 81, 617-624.

Bassler, B. L. (1999). How bacteria talk to each other: regulation of gene expression by quorum sensing. Curr Opin Microbiol 2, 582-587.

Bertani, I. \& Venturi, V. (2004). Regulation of the $\mathrm{N}$-acyl homoserine lactone-dependent quorum-sensing system in rhizosphere Pseudomonas putida WCS358 and cross-talk with the stationaryphase RpoS sigma factor and the global regulator GacA. Appl Environ Microbiol 70, 5493-5502.

Blumer, C., Heeb, S., Pessi, G. \& Haas, D. (1999). Global GacAsteered control of cyanide and exoprotease production in Pseudomonas fluorescens involves specific ribosome binding sites. Proc Natl Acad Sci U S A 96, 14073-14078.

Brazma, A., Hingamp, P., Quackenbush, J. \& 21 other authors (2001). Minimum information about a microarray experiment (MIAME) - toward standards for microarray data. Nat Genet 29, 365-371.

Castric, P. A. (1975). Hydrogen cyanide, a secondary metabolite of Pseudomonas aeruginosa. Can J Microbiol 21, 613-618.

Chancey, S. T., Wood, D. W. \& Pierson, L. S., III (1999). Twocomponent transcriptional regulation of $\mathrm{N}$-acyl-homoserine lactone production in Pseudomonas aureofaciens. Appl Environ Microbiol 65, 2294-2299.

Chatterjee, A., Cui, Y., Yang, H., Collmer, A., Alfano, J. R. \& Chatterjee, A. K. (2003). GacA, the response regulator of a twocomponent system, acts as a master regulator in Pseudomonas syringae pv. tomato DC3000 by controlling regulatory RNA, transcriptional activators, and alternate sigma factors. Mol Plant Microbe Interact 16, 1106-1117.
Chin-A-Woeng, T. F. C., Bloemberg, G. V., van der Bij, A. J. \& 10 other authors (1998). Biocontrol by phenazine-1-carboxamideproducing Pseudomonas chlororaphis PCL1391 of tomato root rot caused by Fusarium oxysporum f. sp. radicis-lycopersici. Mol Plant Microbe Interact 11, 1069-1077.

Chin-A-Woeng, T. F. C., Bloemberg, G. V., Mulders, I. H., Dekkers, L. C. \& Lugtenberg, B. J. J. (2000). Root colonization by phenazine1-carboxamide-producing bacterium Pseudomonas chlororaphis PCL1391 is essential for biocontrol of tomato foot and root rot. Mol Plant Microbe Interact 13, 1340-1345.

Chin-A-Woeng, T. F. C., Thomas-Oates, J. E., Lugtenberg, B. J. J. \& Bloemberg, G. V. (2001a). Introduction of the $p h z H$ gene of Pseudomonas chlororaphis PCL1391 extends the range of biocontrol ability of phenazine-1-carboxylic acid-producing Pseudomonas spp. strains. Mol Plant Microbe Interact 14, 1006-1015.

Chin-A-Woeng, T. F. C., van den Broek, D., de Voer, G., van der Drift, K. M., Tuinman, S., Thomas-Oates, J. E., Lugtenberg, B. J. J. \& Bloemberg, G. V. (2001b). Phenazine-1-carboxamide production in the biocontrol strain Pseudomonas chlororaphis PCL1391 is regulated by multiple factors secreted into the growth medium. Mol Plant Microbe Interact 14, 969-979.

Chin-A-Woeng, T. F. C., Bloemberg, G. V. \& Lugtenberg, B. J. J. (2003). Phenazines and their role in biocontrol by Pseudomonas bacteria. New Phytol 157, 503-523.

Chin-A-Woeng, T. F. C., van den Broek, D., Lugtenberg, B. J. J. \& Bloemberg, G. V. (2005). The Pseudomonas chlororaphis PCL1391 sigma regulator $p s r A$ represses the production of the antifungal metabolite phenazine-1-carboxamide. Mol Plant Microbe Interact 18, 244-253.

Deziel, E., Comeau, Y. \& Villemur, R. (2001). Initiation of biofilm formation by Pseudomonas aeruginosa 57RP correlates with emergence of hyperpiliated and highly adherent phenotypic variants deficient in swimming, swarming, and twitching motilities. J Bacteriol 183, 1195-1204.

Ditta, G., Stanfield, S., Corbin, D. \& Helinski, D. R. (1980). Broad host range DNA cloning system for gram-negative bacteria: construction of a gene bank of Rhizobium meliloti. Proc Natl Acad Sci U S A 77, 7347-7351.

Folders, J., Algra, J., Roelofs, M. S., van Loon, L. C., Tommassen, J. \& Bitter, W. (2001). Characterization of Pseudomonas aeruginosa chitinase, a gradually secreted protein. J Bacteriol 183, 7044-7052.

Fujita, M., Tanaka, K., Takahashi, H. \& Amemura, A. (1994). Transcription of the principal sigma-factor genes, $r p o D$ and $r p o S$, in Pseudomonas aeruginosa is controlled according to the growth phase. Mol Microbiol 13, 1071-1077.

Galperin, M. Y., Nikolskaya, A. N. \& Koonin, E. V. (2001). Novel domains of the prokaryotic two-component signal transduction systems. FEMS Microbiol Lett 203, 11-21.

Haas, D. \& Defago, G. (2005). Biological control of soil-borne pathogens by fluorescent pseudomonads. Nat Rev Microbiol 3, 307-319.

Hanahan, D. (1983). Studies on transformation of Escherichia coli with plasmids. J Mol Biol 166, 557-580.

Heeb, S. \& Haas, D. (2001). Regulatory roles of the GacS/GacA two-component system in plant-associated and other gram-negative bacteria. Mol Plant Microbe Interact 14, 1351-1363.

Heeb, S., Blumer, C. \& Haas, D. (2002). Regulatory RNA as mediator in GacA/RsmA-dependent global control of exoproduct formation in Pseudomonas fluorescens CHA0. J Bacteriol 184, 1046-1056.

Heurlier, K., Williams, F., Heeb, S., Dormond, C., Pessi, G., Singer, D., Camara, M., Williams, P. \& Haas, D. (2004). Positive control of swarming, rhamnolipid synthesis, and lipase production by the 
posttranscriptional RsmA/RsmZ system in Pseudomonas aeruginosa PAO1. J Bacteriol 186, 2936-2945.

Kang, B. R., Cho, B. H., Anderson, A. J. \& Kim, Y. C. (2004). The global regulator GacS of a biocontrol bacterium Pseudomonas chlororaphis $\mathrm{O} 6$ regulates transcription from the rpoS gene encoding a stationary-phase sigma factor and affects survival in oxidative stress. Gene 325, 137-143.

Kojic, M. \& Venturi, V. (2001). Regulation of rpoS gene expression in Pseudomonas: involvement of a TetR family regulator. J Bacteriol 183, 3712-3720.

Kojic, M., Degrassi, G. \& Venturi, V. (1999). Cloning and characterisation of the rpoS gene from plant growth-promoting Pseudomonas putida WCS358: RpoS is not involved in siderophore and homoserine lactone production. Biochim Biophys Acta 1489, 413-420.

Kojic, M., Aguilar, C. \& Venturi, V. (2002). TetR family member PsrA directly binds the Pseudomonas rpoS and psrA promoters. J Bacteriol 184, 2324-2330.

Kovach, M. E., Elzer, P. H., Hill, D. S., Robertson, G. T., Farris, M. A., Roop, R. M. \& Peterson, K. M. (1995). Four new derivatives of the broad-host-range cloning vector pBBR1MCS, carrying different antibiotic-resistance cassettes. Gene 166, 175-176.

Kuiper, I., Bloemberg, G. V., Noreen, S., Thomas-Oates, J. E. \& Lugtenberg, B. J. J. (2001). Increased uptake of putrescine in the rhizosphere inhibits competitive root colonization by Pseudomonas fluorescens strain WCS365. Mol Plant Microbe Interact 14, 1096-1104.

Lange, R. \& Hengge-Aronis, R. (1991). Identification of a central regulator of stationary-phase gene expression in Escherichia coli. Mol Microbiol 5, 49-59.

Laville, J., Voisard, C., Keel, C., Maurhofer, M., Defago, G. \& Haas, D. (1992). Global control in Pseudomonas fluorescens mediating antibiotic synthesis and suppression of black root rot of tobacco. Proc Natl Acad Sci U S A 89, 1562-1566.

Lugtenberg, B. J. J., Chin-A-Woeng, T. F. C. \& Bloemberg, G. V. (2002). Microbe-plant interactions: principles and mechanisms. Antonie Van Leeuwenhoek 81, 373-383.

Milton, D. L., Hardman, A., Camara, M., Chhabra, S. R., Bycroft, B. W., Stewart, G. B. \& Williams, P. (1997). Quorum sensing in Vibrio anguillarum: characterization of the vanI/vanR locus and identification of the autoinducer $\mathrm{N}$-(3-oxodecanoyl)-L-homoserine lactone. J Bacteriol 179, 3004-3012.

Nishikawa, T., Ogawa, K., Kohda, R., Zhixiong, W., Miyasaka, H., Umeda, F., Maeda, I., Kawase, M. \& Yagi, K. (2002). Cloning and molecular analysis of poly(3-hydroxyalkanoate) biosynthesis genes in Pseudomonas aureofaciens. Curr Microbiol 44, 132-135.

Pessi, G. \& Haas, D. (2001). Dual control of hydrogen cyanide biosynthesis by the global activator GacA in Pseudomonas aeruginosa PAO1. FEMS Microbiol Lett 200, 73-78.

Pierson, L. S., III, Keppenne, V. D. \& Wood, D. W. (1994). Phenazine antibiotic biosynthesis in Pseudomonas aureofaciens 30-84 is regulated by PhzR in response to cell density. J Bacteriol 176, 3966-3974.

Qi, Q., Rehm, B. H. \& Steinbüchel, A. (1997). Synthesis of poly(3hydroxyalkanoates) in Escherichia coli expressing the PHA synthase gene phaC2 from Pseudomonas aeruginosa: comparison of $\mathrm{PhaC} 1$ and PhaC2. FEMS Microbiol Lett 157, 155-162.

Ramos-González, M. I. \& Molin, S. (1998). Cloning, sequencing, and phenotypic characterization of the rpoS gene from Pseudomonas putida KT2440. J Bacteriol 180, 3421-3431.

Rashid, M. H., Rajanna, C., Ali, A. \& Karaolis, D. K. (2003). Identification of genes involved in the switch between the smooth and rugose phenotypes of Vibrio cholerae. FEMS Microbiol Lett 227, 113-119.

Rehm, B. H., Kruger, N. \& Steinbuchel, A. (1998). A new metabolic link between fatty acid de novo synthesis and polyhydroxyalkanoic acid synthesis. The phaG gene from Pseudomonas putida KT2440 encodes a 3-hydroxyacyl-acyl carrier protein-coenzyme A transferase. J Biol Chem 273, 24044-24051.

Reimmann, C., Beyeler, M., Latifi, A., Winteler, H., Foglino, M., Lazdunski, A. \& Haas, D. (1997). The global activator GacA of Pseudomonas aeruginosa PAO1 positively controls the production of the autoinducer $\mathrm{N}$-butyryl-homoserine lactone and the formation of the virulence factors pyocyanin, cyanide, and lipase. Mol Microbiol 24, 309-319.

Sacherer, P., Defago, G. \& Haas, D. (1994). Extracellular protease and phospholipase $\mathrm{C}$ are controlled by the global regulatory gene gacA in the biocontrol strain Pseudomonas fluorescens CHA0. FEMS Microbiol Lett 116, 155-160.

Sambrook, J. \& Russell, D. (2001). Molecular Cloning: a Laboratory Manual, 3rd edn. Cold Spring Harbor, NY: Cold Spring Harbor Laboratory.

Sarniguet, A., Kraus, J., Henkels, M. D., Muehlchen, A. M. \& Loper, J. E. (1995). The sigma factor $\sigma^{\mathrm{S}}$ affects antibiotic production and biological control activity of Pseudomonas fluorescens Pf-5. Proc Natl Acad Sci U S A 92, 12255-12259.

Schmidt-Eisenlohr, H., Gast, A. \& Baron, C. (2003). Inactivation of gacS does not affect the competitiveness of Pseudomonas chlororaphis in the Arabidopsis thaliana rhizosphere. Appl Environ Microbiol 69, $1817-1826$

Schuster, M., Hawkins, A. C., Harwood, C. S. \& Greenberg, E. P. (2004). The Pseudomonas aeruginosa RpoS regulon and its relationship to quorum sensing. Mol Microbiol 51, 973-985.

Suh, S. J., Silo-Suh, L., Woods, D. E., Hassett, D. J., West, S. E. \& Ohman, D. E. (1999). Effect of rpoS mutation on the stress response and expression of virulence factors in Pseudomonas aeruginosa. J Bacteriol 181, 3890-3897.

van Rij, E. T., Wesselink, M., Chin-A-Woeng, T. F. C., Bloemberg, G. V. \& Lugtenberg, B. J. J. (2004). Influence of environmental conditions on the production of phenazine-1-carboxamide by Pseudomonas chlororaphis PCL1391. Mol Plant Microbe Interact 17, 557-566.

van Rij, E. T., Girard, G., Lugtenberg, B. J. J. \& Bloemberg, G. V. (2005). Influence of fusaric acid on phenazine-1-carboxamide synthesis and gene expression of Pseudomonas chlororaphis strain PCL1391. Microbiology 151, 2805-2814.

Whistler, C. A. \& Pierson, L. S., III (2003). Repression of phenazine antibiotic production in Pseudomonas aureofaciens strain 30-84 by RpeA. J Bacteriol 185, 3718-3725.

Whistler, C. A., Corbell, N. A., Sarniguet, A., Ream, W. \& Loper, J. E. (1998). The two-component regulators GacS and GacA influence accumulation of the stationary-phase sigma factor $\sigma^{\mathrm{S}}$ and the stress response in Pseudomonas fluorescens Pf-5. J Bacteriol 180, 6635-6641.

Whiteley, M., Parsek, M. R. \& Greenberg, E. P. (2000). Regulation of quorum sensing by RpoS in Pseudomonas aeruginosa. J Bacteriol 182, 4356-4360.

Wood, D. W. \& Pierson, L. S., III (1996). The phzI gene of Pseudomonas aureofaciens $30-84$ is responsible for the production of a diffusible signal required for phenazine antibiotic production. Gene 168, 49-53.

Wood, D. W., Gong, F., Daykin, M. M., Williams, P. \& Pierson, L. S., III (1997). $\mathrm{N}$-acyl-homoserine lactone-mediated regulation of phenazine gene expression by Pseudomonas aureofaciens 30-84 in the wheat rhizosphere. J Bacteriol 179, 7663-7670.

Zuber, S., Carruthers, F., Keel, C. \& 8 other authors (2003). GacS sensor domains pertinent to the regulation of exoproduct formation and to the biocontrol potential of Pseudomonas fluorescens CHA0. Mol Plant Microbe Interact 16, 634-644. 